\title{
The Role of Bio-renewables in National Energy and Transportation Systems Portfolio Planning for Low Carbon Economy
}

Venkat Krishnan $^{1,2 *}$ and James D. McCalley ${ }^{1}$

${ }^{1}$ Electrical and Computer Engineering Department, Iowa State University, Ames, IA 50014, USA

2 currently at National Renewable Energy Laboratory (NREL), Golden, CO 80401, USA

* - corresponding author, venky83krish@gmail.com

Abstract-Bio-power and biofuels are promising alternative energy resources. This paper investigates their role in the long-term U.S. national energy and transportation portfolio planning, while considering the competition among other energy options. The paper presents a systematic modeling framework for integrating biomass pathways to the energy and transportation systems, and also captures the geographical variation in the feedstock availability and cost across the U.S. The paper then presents two different case studies- energy sector planning and integrated energy \& transportation sectors planning. The studies reveal long-term cost and emission savings from bio-renewables, where the bulk of benefits are observed due to biofuels (with bio-power production limited by feedstock prices). Under a $40 \% \mathrm{CO}_{2}$ emissions reduction scenario over the next 40 years, penetration of bio-renewables promise up to 10-Trillion USD (2010\$) savings in system costs (investments and operational). Simulations also show that the impediment with bio-renewable penetration is mostly influenced by the availability of low-cost feedstock, specifically for bio-power production. According to current estimation of long-term feedstock availability, U.S will be able to power upto 150 Billion Gallons Year (BGY) (or approx. 560*10 $10^{9}$ liters per year) bio-refinery capacity around 2020s, and about $200 \mathrm{BGY}$ (or approx. $750 * 10^{9}$ liters per year) by 2050 .

Index Terms-Bio-power, Biofuels, Feedstock, Energy infrastructure planning, Environmental impacts

\section{NOMENClATURE}

- $t, z$ - time period

- $i, j-$ energy sector nodes (at regional scale) and arcs (representing various components, e.g., generators, transmission lines).

- $x, y$ - transportation sector nodes (at state level) and arcs, e.g., pipelines, interstate passenger transportation

- $k$ - commodity transported ( $k=e k$ is coal or biomass for energy; $k=f k$ is non-energy freight; $k=p$ is passengers)

- $m$-interstate transportation mode (fleet or vehicle type)

Decision variables

- $e_{(i, j)}(t)$ - energy flow in the arc $(i, j)$ at time $t$

- $e_{(i, j)}^{s}(t)$ - energy flow through arc $(i, j)$ 's supply curve segment $s$ at time $t$

- $p_{(i, j)}(t)$ - number of LDVs of type $i$ in region $j$ at time $t$

- $f_{(x, y, k, m)}(t)$ - number of interstate vehicles of type $m$ to transport commodity $k$ across arc $(x, y)$ at time $t$

- $\operatorname{eInv}_{(i, j)}(t)$ - investment in infrastructure $(i, j)$ at time $t$

- $\operatorname{pInv}_{(i, j)}(t)$ - investment in LDV $i$ at time $t$

- $f \operatorname{Inv}(x, y, m)(t)$ - fleet investments of type $m$ across transportation arc $(x, y)$ at time $t$

Parameters and constants

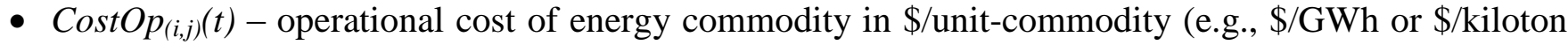
or $\$$ gallon) through arc $(i, j)$ at time $t$ (where 1 gallon $\approx 3.78$ liters)

- $\operatorname{Cost} O p_{(i, j)}^{s}(t)$ - operational cost of energy commodity in \$/unit-commodity through arc $(i, j)$ 's supply curve segment $s$ at time $t$

- $\operatorname{Cost} O p^{p}{ }_{(i, j)}(t)$ - operational cost of LDV $i$ in $\$ /$ vehicle in region $j$ at time $t$ 
- $\operatorname{CostOp}(x, y, k, m)(t)$ - operational cost of transportation by interstate mode $m$ in $\$ /$ vehicle-mile to transport commodity $k$ across arc $(x, y)$ at time $t$

- $\operatorname{CostInv}(i, j)(t)$ - investment cost in $\$ /$ unit-capacity for arc $(i, j)$

- $\operatorname{CostpInv}_{(i, j)}(t)$ - investment cost of LDV $i$ in $\$ /$ vehicle in region $j$ at time $t$

- $\operatorname{CostfInv}_{(x, y, m)}(t)$ - investment cost of mode $m$ in $\$ /$ vehicle across arc $(x, y)$ at time $t$

- $r$-discount rate

- $\eta_{(i, j)}, \eta_{(x, y, k, m)}$ - arc efficiency parameters

- $d_{j}^{e}(t)$ - nodal energy demanded (electricity, petroleum, or gas) at region $j$ at time $t$.

- $d^{e T}{ }_{j}(t)$ - nodal energy demand (fuel or electricity) imposed by transportation systems in region $j$ at time $t$.

- $d^{p T}{ }_{j}(t)$ - LDVs demanded in region $j$ at time $t$

- $d^{T}{ }_{(x, y, k)}(t)$ - Interstate transportation demand for commodity $k$ across arc $(x, y)$ at time $t$ (bi-directional quantity); where $k=f k$ is non-energy freight demand and $k=p$ is passenger demand

- $h_{e k}(t)$ - energy content of the energy commodity $e k$ (coal or biomass) in GWh/kiloton

- $\alpha_{(x, y)}^{j}$ - proportion of energy for bi-directional transportation across arc $(x, y)$ coming from region $j$

- fuel $C_{m}(t)$ - fuel/energy consumption by mode $m$, (e.g., gallon/vehicle-mile or GWh/vehicle-mile) at time $t$

- $l_{(i, j)}^{p}(t)$ - average miles travelled by LDV $i$ in region $j$

- $l_{(x, y)}(\mathrm{t})$ - distance between states $x$ and $y$ in miles

- $l b e_{(i, j)}(t), u b e_{(i, j)}(t)$ - lower and upper existing capacities (accounts periodic retirements for infrastructures) of energy arc at time $t$

- $u b e_{(i, j)}^{s}(t)$ - Upper bound on the supply curve's segment $s$

- $c a p \_e_{(i, j)}(t)$ - total arc capacity at time $t$, including existing capacity and new investments

- $\operatorname{lbeInv}(i, j)(t), u b e \operatorname{Inv}(i, j)(t)$ - minimum and maximum limits on infrastructure investments at time $t$

- $u b p_{(i, j)}(t)$ - Upper bound on the LDV $i$ existing fleet

- $c a p \_p_{(i, j)}(t)$ - total LDV $i$ fleet size in region $j$ at time $t$, including existing size and new investments

- $\operatorname{lbpInv}_{(i, j)}(t), u b p \operatorname{In} v_{(i, j)}(t)$ - minimum and maximum limits on LDV $i$ investments at time $t$

- $l b f_{(x, y, m)}(t), u b f_{(x, y, m)}(t)$ - lower and upper interstate fleet capacity for mode $m$ across arc $(x, y)$ at time $t$

- $\operatorname{cap} \__{(x, y, m)}(t)$ - total capacity for mode $m$ across arc $(x, y)$ at time $t$, including existing size and new investments

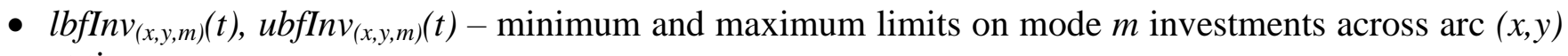
at time $t$

- inv_start - investment starting period

- life, plife, flife - infrastructure lifespan (electric, LDV and interstate fleet) in years

- $I(t-z \leq$ life $)$ - indicator function on available life of an infrastructure (applies to plife and flife also)

\section{INTRODUCTION}

37 NERGY generation by fossil fuel combustion is one of the major contributors to the anthropogenic 38 carbon-dioxide $\left(\mathrm{CO}_{2}\right)$ emissions leading to global warming concerns. In the U.S., $\mathrm{CO}_{2}$ emitted by burning fossil fuels such as coal, gas and petroleum for electricity generation, transportation and other (industrial, residential and commercial) purposes contributed to about $79 \%$ of the total national greenhouse gas (GHG) emissions on $\mathrm{CO}_{2}$ equivalent $\left(\mathrm{CO}_{2} \mathrm{e}\right)$ [1], of which electricity generation $(\sim 41 \%)$ and transportation $(\sim 33 \%)$ have been the two major sources. In this context, long-term planning efforts towards low carbon emissions in the electricity sector have been mainly in terms of integrating variable renewables and addressing the associated system flexibility needs [2], rendering the fossil-fired power plants clean using carbon capture and emission control devices [3], and designing market policies to penalize emissions [4]. In the transportation sector, efforts have been towards using alternative fuels such as natural gas, 
1 hydrogen, ethanol, and electricity [5,6]. Acknowledging the perspective that the path towards success would comprise all the available solution strategies, this paper explores the role of biomass based renewable products (also known as bio-renewables, namely biofuels and bio-power) in decarbonizing and sustaining the future economy [7].

Biomass feed-stocks subject to thermo-chemical and bio-chemical conversion processes have tremendous potential to supply bio-power and biofuels at a highly reduced emissions rate $[8,9,10]$. This emission savings is possible because agriculture- and forestry-based biomass feed-stocks facilitate sequestering carbon from the environment during their growth, and hence an integrated study of biomass with other sectors reveal the existence of near net-carbon-zero pathways across the entire energy production-transportation-conversion-consumption cycle [9]. Assessments [11] do indicate that significant emission savings can be ensured by following sustainable practices at the biomass production and processing stages, such as choosing the best feedstock, geographical location, land-use practices, agrochemical uses, feedstock drying and transportation means. Furthermore, to circumvent issues related to food supply and to increase the economic viability, pathways involving secondary feed-stocks (residues and energy crops) and genetically modified crops (with high growth rate \& energy content) are pursued.

Given the above background, this paper investigates the national scale potential of bio-renewables to compete with and complement other energy and transportation infrastructure expansion solutions, and assesses the long-term impacts of the resulting portfolios in terms of cost and emissions. There have been many studies that have looked into optimizing the siting of biomass processing plants (for bio-power and biofuels) in a smaller geographical regions for some future year [12, 13], considering the feedstock production locations, impact on local transportation, and finally drawing conclusions on the biorenewables economics. However, fewer models and methodologies are able to plan bio-renewable infrastructures considering their long-term roles in both energy and transportation sectors, and assess their impacts at the national scale. A national scale study performed by the researchers at the RAND corporation estimated about $37 \%$ of the U.S. national energy coming from biomass for realizing $25 \%$ renewable portfolio standard (RPS) mandate by the year 2025 [14]. The National Renewable Energy Laboratory (NREL) envisions biomass to provide at best about $15.2 \%$ of national generation in the year 2050 under a $80 \%$ renewable energy scenario [15]. Given that the above two are electric-only planning studies, the Energy Information Administration (EIA) provides forecasts based on the National Energy Modeling System (NEMS), which simulates energy and transportation sector operations for a given future portfolio. The 2014 issue of Annual Energy Outlook (AEO), released by EIA, forecasts increasing penetration of bio-renewables by the year 2040, especially $27 \%$ of the renewable energy coming from bio-power [16]. In comparison to NEMS, which is an equilibrium model that cost-effectively balances supply-demand separately within each sector, this paper provides planning perspectives from a multi-sector integrated optimization model.

This paper presents a planning model that integrates biomass pathways into a 40-year multi-period optimization model called NETPLAN, which co-optimizes the investments and operations in interdependent energy and transportation infrastructure systems [17, 18]. The presented model helps to find the most promising investment strategies across both the energy and transportation sectors. The paper also captures the geographical characterization of the biomass feed-stocks across the nation in terms of their cost and availability. This further enhances the model, and facilitates assessing the role of biorenewables among other competing options and helps in ascertaining which bio-renewable technologies at what location can help the drive towards low carbon economy. Finally, this paper utilizes the model to simulate many planning scenarios under different assumptions, and assesses the impact of increasing penetration of bio-renewable facilities (bio-power and biofuels) on the national long-term planning cost and emissions.

The organization of the paper is as follows. Section III discusses the integration of the biomass network into energy and transportation planning model. Section IV describes the formulation of the long-term 
infrastructure planning model-NETPLAN integrated with biomass network, and section V presents the numerical results for different scenarios and draws insights on the role of bio-renewables. Section VI presents the conclusions, and Section VII is an appendix that provides details on modeling and data assumptions for energy and transportation system models. It is to be noted that this section provides centralized assumptions for various parameters that make up the long-term planning model. The results discussed in Section V are therefore based on the traditional deterministic long-term planning paradigm, without accommodating uncertainties in the parameter estimations as will be done in a typical probabilistic or stochastic long term planning model [19] or a dynamic model with periodic parameter updates [20]. Embedding all such modeling improvements to accommodate stochasticity in future parameters is beyond the scope of this paper's focus, however Section V provides additional scenarios wherein the changes in infrastructure investment decisions with respect to different scenario assumptions are discussed.

\section{BIOMASS IN INTERDEPENDENT ENERGY AND TRANSPORTATION INFRASTRUCTURE SYSTEMS}

Integrating biomass pathways with a national energy and transportation planning model will enable pursuing the answers to several interesting questions, such as: What will be the market penetration of biorenewables when competed with all the major energy options? Which scenarios favor or disfavor biorenewable penetration? What is the best mix of electricity, petroleum, and biofuels to supply the national automotive needs? What is the impact of bio-renewables on national emissions? What is the best mix of feedstock and conversion plants? The focus of this paper is to investigate the answers to some of these questions in the context of long-term planning towards a low carbon economy. In order to do that we will require a planning model that can integrate biomass pathways into energy and transportation sectors. This section discusses such a modeling platform, and is divided into 3 subsections on: a) the various biomass pathways from feedstock to energy production, b) how biomass options can be modeled within national scale interdependent energy and transportation systems, and c) what is the biomass feedstock availability, cost and performance characteristics ${ }^{1}$, and how they vary geographically across the U.S. nation.

\section{A. Biomass feedstock-to-energy production pathways}

Figure 1 shows the biomass network, beginning from feedstock to production of electricity and fuel. The major sources of feedstock, some of which are shown in Fig. 1, are agriculture residues/wastes, forestry residues, industrial wastes, municipal solid wastes (MSW), sewage sludge, animal manure, food and second-generation energy crops. The processed feedstocks are transported through trucks or trailers, and in the case of longer distance through railways, to the conversion plants. Dry feedstock subject to combustion, gasification (syngas), and co-firing are used to produce power and heat (combined heat and power (CHP) facilities). Wet biomass such as animal manure, sewage sludge and MSW from landfill sites are subject to anaerobic digestion (AD) to produce biogas, which is used to produce electricity. Feedstocks subject to fast pyrolysis and hydro-processing in bio-refineries are converted into bio-oil, from which dropin bio-fuels, namely bio-diesel or ethanol are obtained for supplying transportation needs [21]. This bio-oil can also be used for producing power through gasification process of the liquid fuel obtained from the fast pyrolysis. This kind of power generation technology is usually known as integrated pyrolysis combined cycle (IPCC). Additionally, the gas and char obtained as side-products from the fast pyrolysis process can also be subjected to combustion to produce electricity, thereby increasing the efficiency of the biorefineries (generally known as integrated bio-refineries that have higher efficiency, a concept similar to CHP).

\footnotetext{
${ }^{1}$ Data presented in this paper are obtained from various references cited and converted to appropriate units as required by the planning model described.
} 


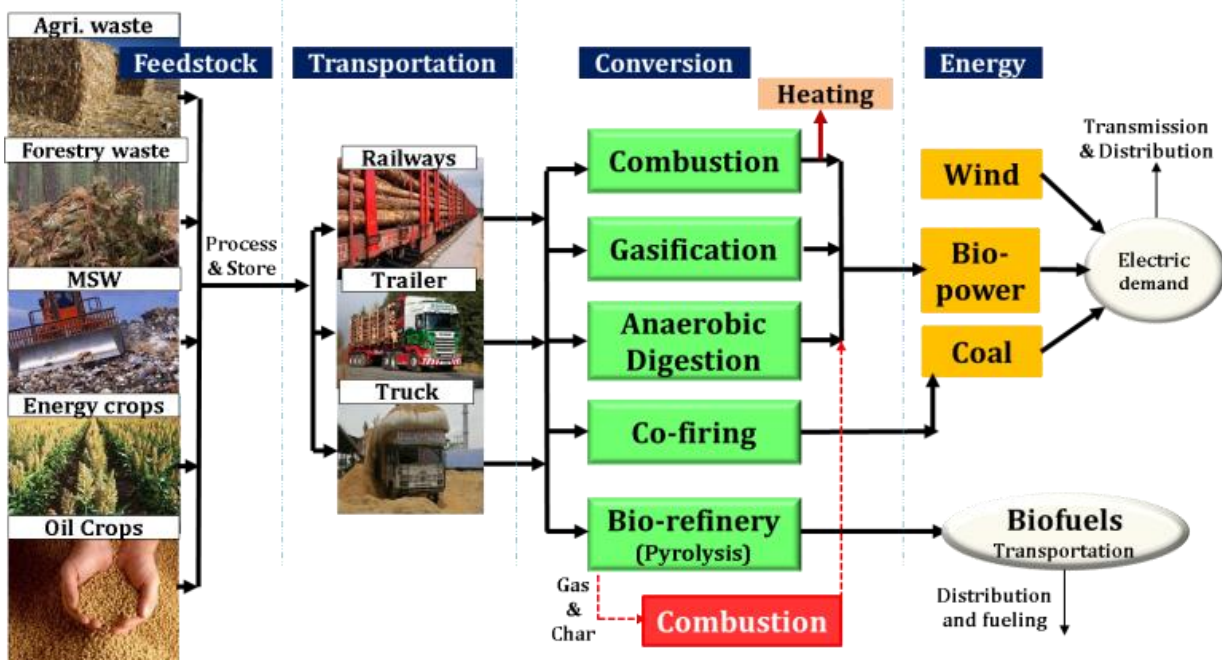

Fig. 1 Feedstock-to-energy production pathways

\section{B. National interdependent infrastructure systems model}

The key aspect of this paper is to assess the market potential of bio-renewables in conjunction with other major competing energy options in the country. Such a nation-wide model will require capturing geographical variation in energy and transportation demand, resource capacities and cost, transfer capacities, and network topology. Such information helps in strategically siting capital intensive infrastructures for long-term economic benefits and sustainability. However to reduce the model size and computational burden involved in planning at national scale, some level of system aggregation must be done. Figure 2 shows the model of the energy network, where four different yet interconnected subsystems aggregated at the state level are presented, namely coal, natural gas, biomass, and electricity sub-systems. At the intrastate level, the fuel/feedstock production, transportation, conversion and demands are represented. The intrastate nodal demands include electricity (EL), gas for heating (NT), and light duty vehicles, LDV, (VD); all of these inputs exogenous to the model. At the interstate level, electric transmission lines, gas pipelines, and arcs for coal, biomass, freight and passenger transportation respectively are represented. It should be noted that though biomass and coal generally fall within the category of freight commodities, they are accounted separately as "freight commodities for energy" since the quantity of such commodities transported depend on the generation portfolio, while demand for the remaining interstate freight and passenger transportation are specified exogenously. The gas network model consists of arcs that represent aggregated gas production (NP-NT), storage (NT-NS), pipeline (NTET), and gas turbine (ET-EL) and combined cycle unit (not shown in the figure). The coal network model has production $(\mathrm{CP}-1 \mathrm{~T})$, transportation (1T-EC), and coal generation (EC-EL). Here 1T refers to a specific coal variety, as the model can accommodate different varieties of coal in each state. Similarly, the biomass network consists of feedstock production (BP-2T), transportation (2T-EB and 2T-BR) and conversion facilities (EB-EL, BR-GD and BR-DD); where for instance 2T, 3T, and 4T denote feedstock varieties. The electricity network consists of aggregated generation of various types, demand (EL), and the interstate transmission lines (EL-EL). Apart from these, the model also includes nuclear generation and petroleum that serve energy and transportation demands respectively. The flow limits of various arcs are set by the capacity of respective infrastructure components, and are allowed to expand. The long-term planning model is driven by the periodic needs to meet the operational demands and optimally expand the associated resource and network to accommodate demand increase and infrastructure retirements.

In order to reduce the computational burden, in this paper we reduce the national model further as shown in Fig. 3, where the conversion facilities, energy transmission and energy demand (electricity and transportation fuel use) in the system are aggregated at the inter-regional level, i.e., several states are grouped to form different energy regions. However, the state-level characterizations are still maintained for 
energy resources and transportation pathways, namely for feedstocks, coal, gas, pipelines, transportation arcs, and interstate freight $\&$ passenger transportation demands. Each state supplies the energy needs in the region within which it is situated and is also connected via transportation arcs to the adjacent states, thereby facilitating inter-regional energy transfers using certain interstate corridors. Section IV will shed 5 further light on the mathematical formulation of this long-term energy and transportation planning model, 6 integrated with biomass pathways.

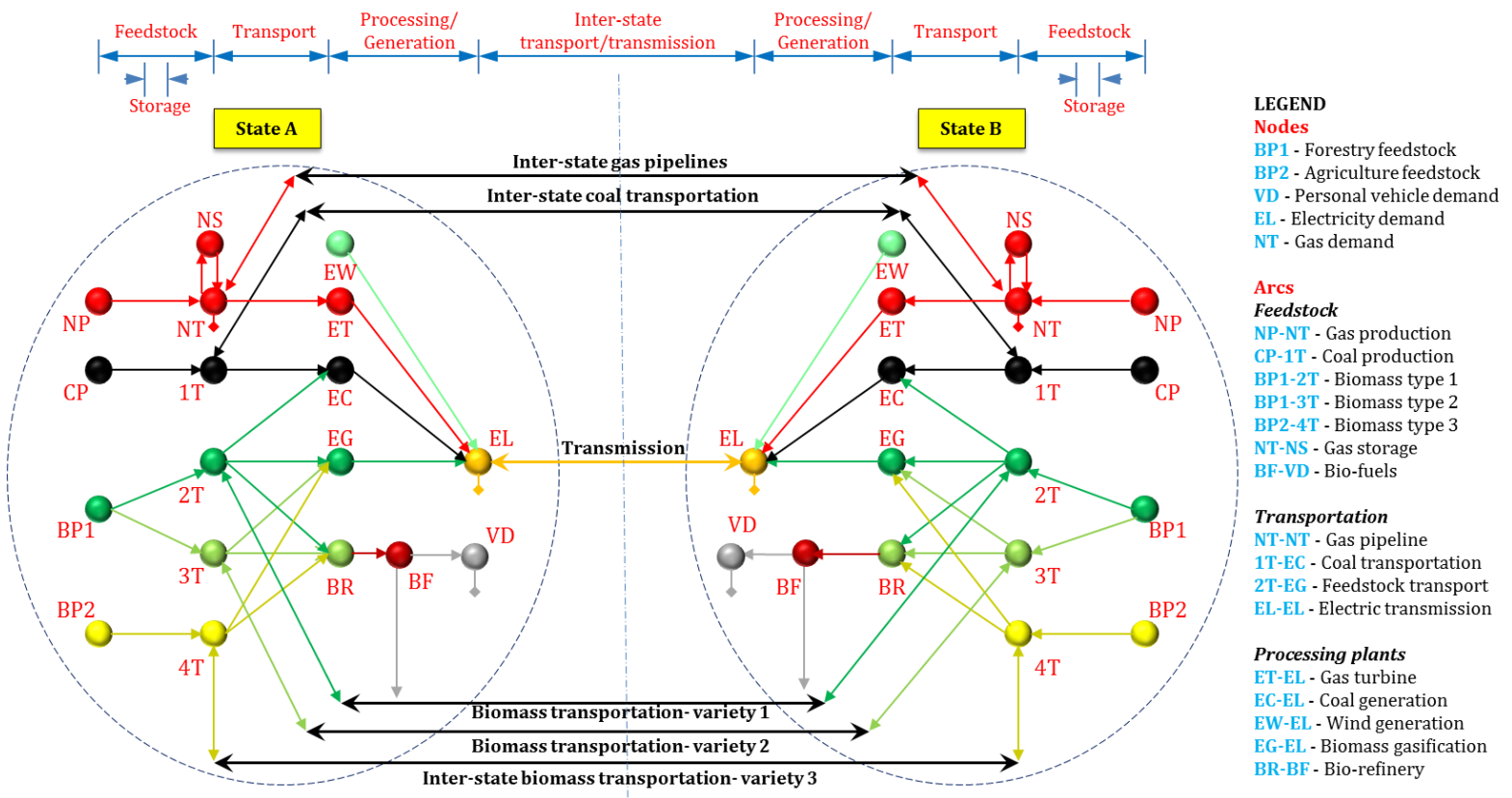

Fig. 2 Biomass pathways integrated into energy system- interstate aggregation

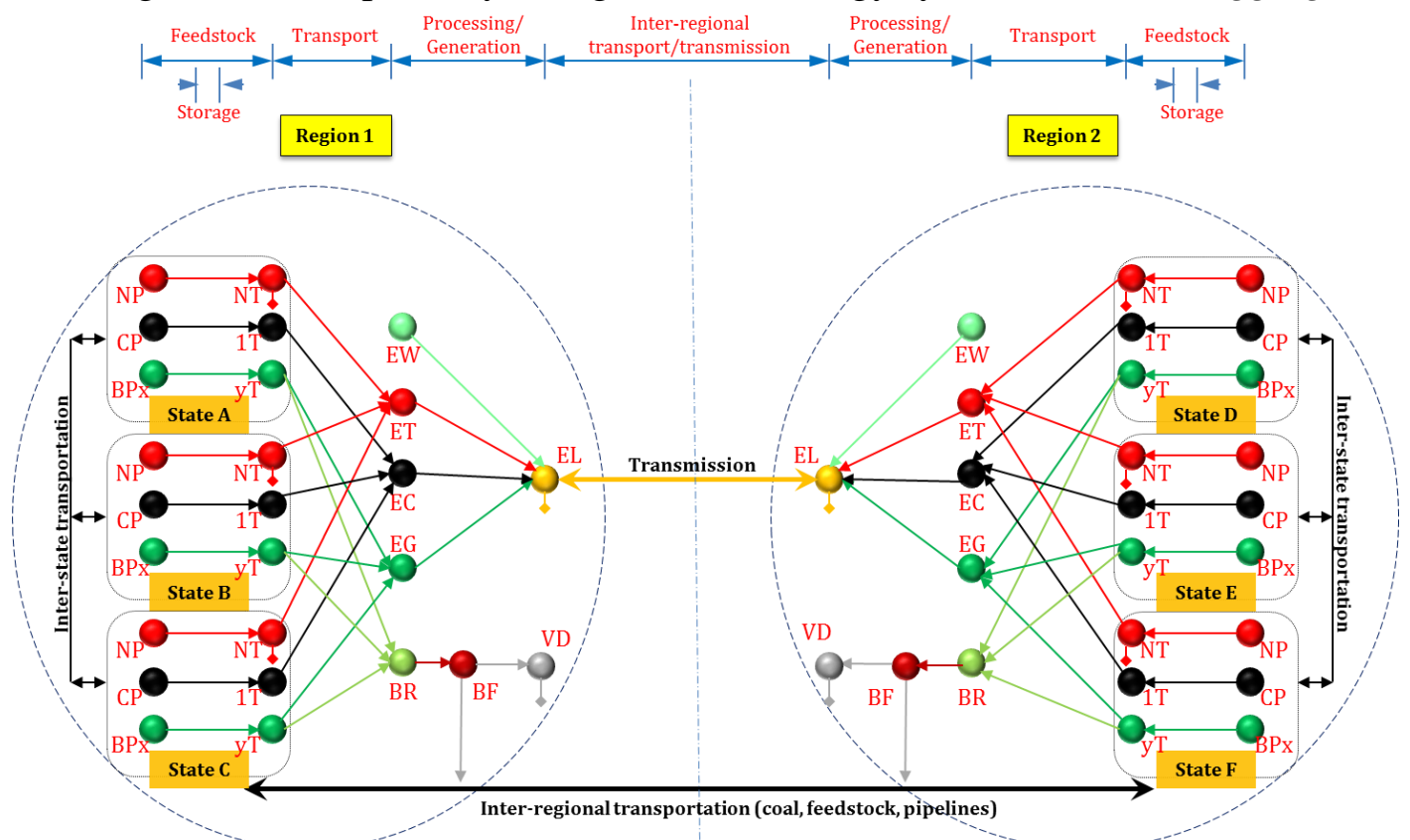

Fig. 3 Biomass pathways integrated into energy system- inter-regional aggregation

C. Biomass feedstock: availability, cost and characteristics

This section focusses on the geographical characterization of the biomass feedstock and their performance measures for energy conversion processes; which will provide important information for optimizing bio-renewables along with other energy options for national energy needs. Appendix sections 
1 transportation infrastructure components, including the various generation and transportation technologies, their cost and performance metrics, and conventional fuel prices.

The U.S. Departments of Energy (DOE) and Agriculture (USDA) had done a nation-wide study in the year 2005 on the technical feasibility of a billion ton (generally known as billion ton study (2005 BTS)) annual feedstock supply [22]. The study concluded that there is potential for about 1.366 billion dry tons per year in the contiguous U.S. considering only resources from forestland (includes fuel wood and residues from wood processing mills, pulp \& paper mills, urban wood, and logging \& site clearing operations) and agricultural land (includes crop residues, perennial crops, grains, animal manures, and process residues). The study assumed a number of factors regarding the availability of forestlands (excluding inaccessible and environmentally sensitive lands) and agricultural lands, equipment capabilities and limitations, tilling methods, yields, and manure usage in order to ensure the estimated biomass resources are annually recovered in a sustainable manner, and still the demands for food, feed, and exports are met. Later in 2005, Milbrandt at NREL [23] developed methodology to estimate biomass resources currently available across the U.S. at the county level. NREL has published these data as maps for different feedstock, namely crop residues, forest and primary mill residues, secondary mill and urban wood waste, methane emissions from landfills, domestic wastewater treatment, and animal manure [24], which reveal North-East, Mid-West and Western U.S. states to be particularly rich in biomass. In 2011, Oak Ridge National Laboratory (ORNL) in collaboration with USDOE published an updated county-level estimate of 2005 BTS [25], which adopted a more rigorous consideration of factors influencing sustainable biomass resource recovery and also included supply curves (Farmgate price vs. availability) for individual feedstocks until the year 2030. These data, which forms the basis for this paper, comprise the Biomass Knowledge Discovery Framework (BKDF) available at [26].

Following BKDF, in this paper we model three broad categories of feedstocks: primary agricultural resources, forest resources and secondary resources. Primary agricultural resources comprise of barley $\&$ barley straw, corn \& corn stover, oats \& oats straw, sorghum \& sorghum stubble, wheat \& wheat-straw, cotton, hay, rice, soybeans, annual energy crops, perennial grass, and coppice $\&$ non-coppice woody crops. Forest resources include conventional wood, logging residues, simulated thinnings from forestlands, and treatment thinnings; all estimated both including and excluding federal lands. Finally, the secondary resources include mill residues, urban wood wastes (construction and demolition), municipal solid waste, cotton trash \& residue, animal fats and waste oils, manure, orchard \& vineyard prunings, rice hulls, rice straw, sugarcane trash, and wheat dust. The availability data for these feedstocks from 2010-2030 were converted to a common unit (kiloton/year (1 thousand ton $=1$ kiloton) $)$ and aggregated at a state-by-state level into the three broad feedstock categories. Beyond the year 2030 until the end of the 40 -year planning horizon (year 2049), the model assumes the feedstock availability at each state to grow at a rate which is $50 \%$ of the growth rate seen in year 2030. The price in the supply curves used in this model for primary agricultural feedstock ranges from $\$ 40-\$ 80 /$ metric-ton, for forest resources from $\$ 10-\$ 200 /$ metric-ton, and for secondary resources from $\$ 10-\$ 60 /$ metric-ton; all at an interval of $\$ 10$. In the BKDF, the state-wise availability data for primary agricultural resources are also given for scenarios that assumed high energy crop yields (higher by $1 \%$ to $4 \%$ than the baseline yield). We consider the $4 \%$ high yield scenario for this study, in addition to the baseline scenario. Table 1 shows the aggregated annual minimum and maximum biomass resources (in kiloton/year) estimated at various years for the entire U.S., available at the appropriate price. It is seen that at the minimum offer price for each feedstock category, the national biomass potential currently is slightly above 0.7 billion ton per year (BTY); and assuming a very high yield for energy crops, there is potential to recover 1 BTY in the next 10 years. At higher Farmgate prices, there is possibility to recover $1 \mathrm{BTY}$ even now and reach $2 \mathrm{BTY}$ in the next 15 years. It is also clearly observed that at low Farmgate prices almost 99\% of the annual resources come from primary agricultural feedstock, and at high Farmgate prices they still contribute up to $60-80 \%$ of the total national potential. 
Table 1 Estimated annual biomass resource capacity in U.S. (source: BKDF)

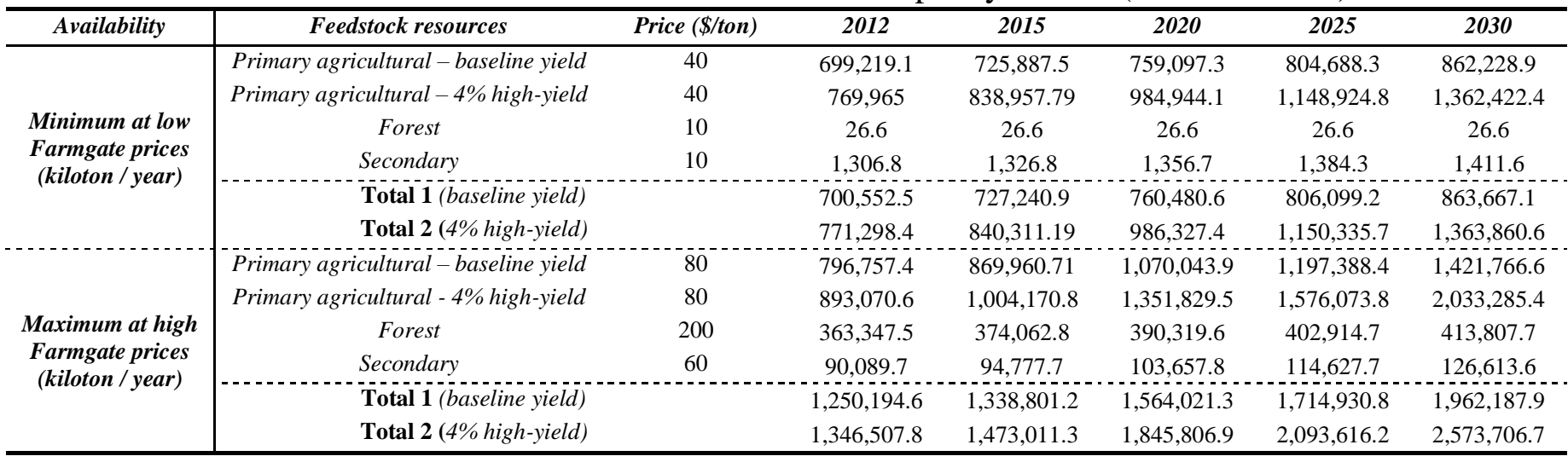

Figures 4, 5 and 6 (created using StatPlanet mapping software [27]) show the geographical resource availability of primary agricultural, forest and secondary feedstocks over the U.S., respectively. Each set of figures use different colors to differentiate between the feedstock types, however the lower end of the spectrum in all figures look very closer though their scalar values are different as indicated by the data labels and the legends. Figures 4 (a-b) shows the primary agricultural resources at $\$ 60 /$ ton for the baseline yield scenario in years 2015 and 2030 respectively, and Fig. 4 (c) shows the same but for the high yield scenario in year 2030. It is observed that these resources are recovered significantly from the Mid-West, and as years pass by their growth rate is higher in the Mid-West and East. Figures 5 (a-b) shows the forest resources at $\$ 60 /$ ton in years 2015 and 2030 respectively, and Fig. 5 (c) shows the same but at \$200/ton in year 2030. Interestingly, the geographical spread of forest resources are in the South, South-East, NorthEast and North-West; quite complimentary to the primary agricultural feedstocks. Finally, the secondary resources shown in Fig. 6 (a-b) for the years 2015 and 2030 at $\$ 60 /$ ton is available through the U.S. (mainly due to the presence of landfill sites and methane emissions), with significant presence in the South, South-East, parts of Mid-West (the states along MN to AR) and West (California). As mentioned, these costs are Farmgate prices for biomass production, and not the price at which the feedstock is delivered at the conversion facilities. Hence an additional cost of $\$ 20 /$ ton is attributed to the biomass production in the model to reflect the average costs involved in processing (balling, drying \& storing), and handling and transporting the feedstock to the local power plants and refineries [28].

With regards to emissions, though biomass sequesters $\mathrm{CO}_{2}$ from the atmosphere, which is accounted in the energy conversion process to render it carbon-zero, nevertheless there are energy and chemical (manure, electricity \& natural gas) consumptions in biomass production, processing and local transportation. While the national scale model captures interstate transportation explicitly (i.e., their cost \& emissions), the emissions at intrastate or local transportation and biomass processing have to be estimated and attributed to the feedstock production process. Table 2 provides an estimate of these emissions in short ton per kiloton feedstock production under good practices such as low usage of nitrogen based fertilizers, siting conversion facilities closer to the farm thereby requiring less transportation, and drying using heat from power plants (CHP) [29, 30, 31]. Table 2 also provides higher-end estimate of these emissions for primary agricultural and forestry resources assuming worst practices such as long-distance and frequent transportations of feedstock, excessive nitrogen fertilizer use, losses in wood chipping or forest clearing stages, and impacts due to land use changes (i.e., if converting fallow land or grass land) [29, 31]. The secondary resources are treated differently, in that the nature of practices affect the emissions credit they offer by virtue of their usage in the energy production, thus avoiding emissions from landfill sites. There are other instances when certain clean wood waste or poultry litter, instead of being dumped in landfill sites, can have excellent reuse, in which case the emission credits of using such secondary feedstock in energy production is less attractive and may lead to more emissions [31]. Therefore the average emission estimates for both good and worst scenarios of secondary resources are provided in Table 2. 

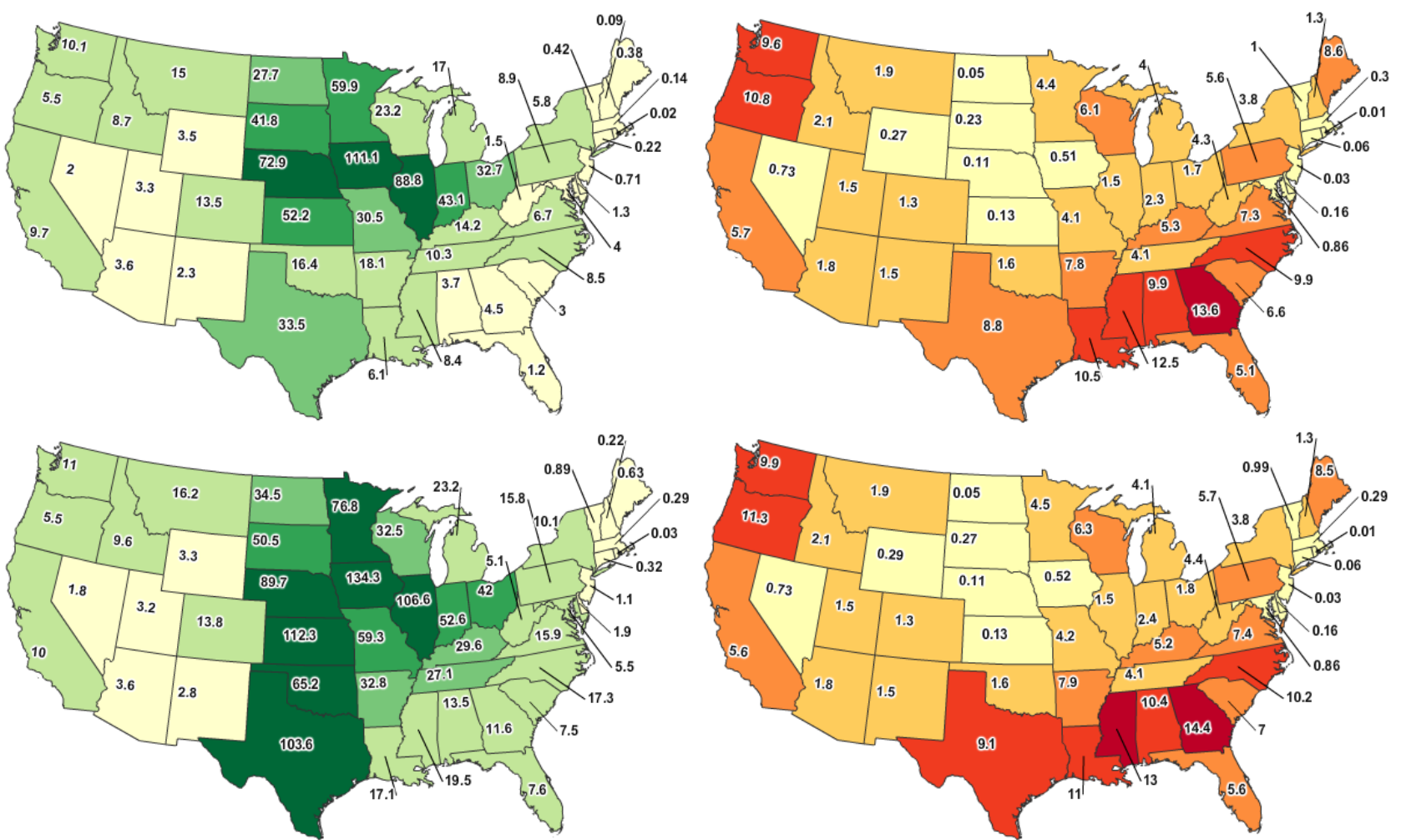

2
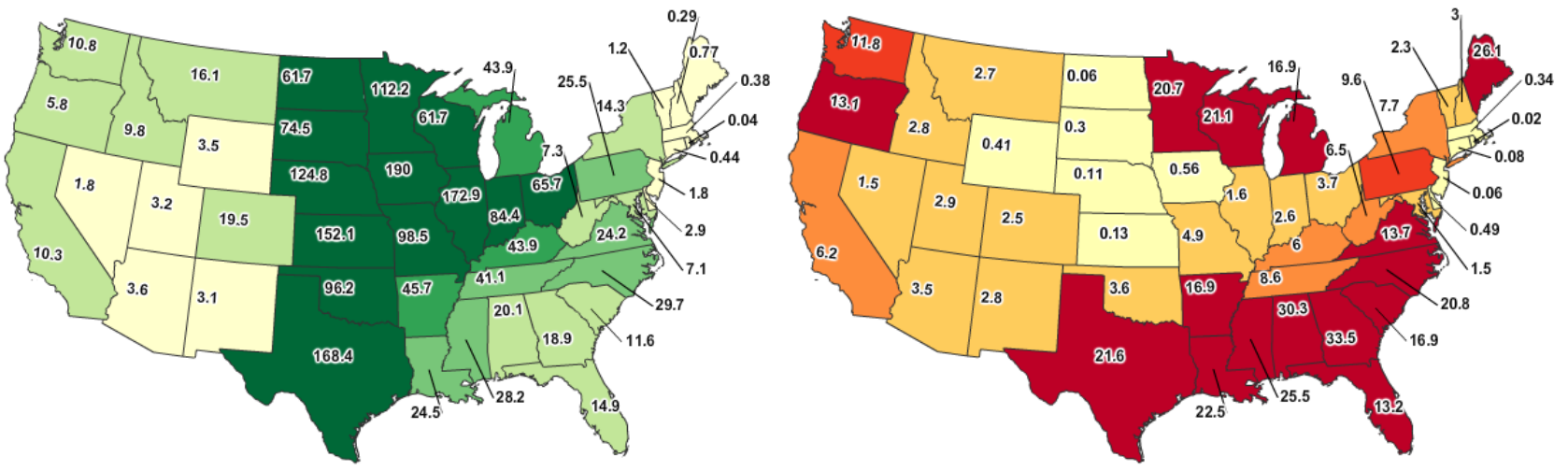

Fig. 5 Forestry feedstock: (a) Year 2015 at $\$ 60 /$ ton, (b) Year 2030 at $\$ 60 /$ ton, and (c) Year 2030 at $\$ 200 /$ ton

(a) Year 2015, (b) Year 2030, and (c) Year 2030 high-yield
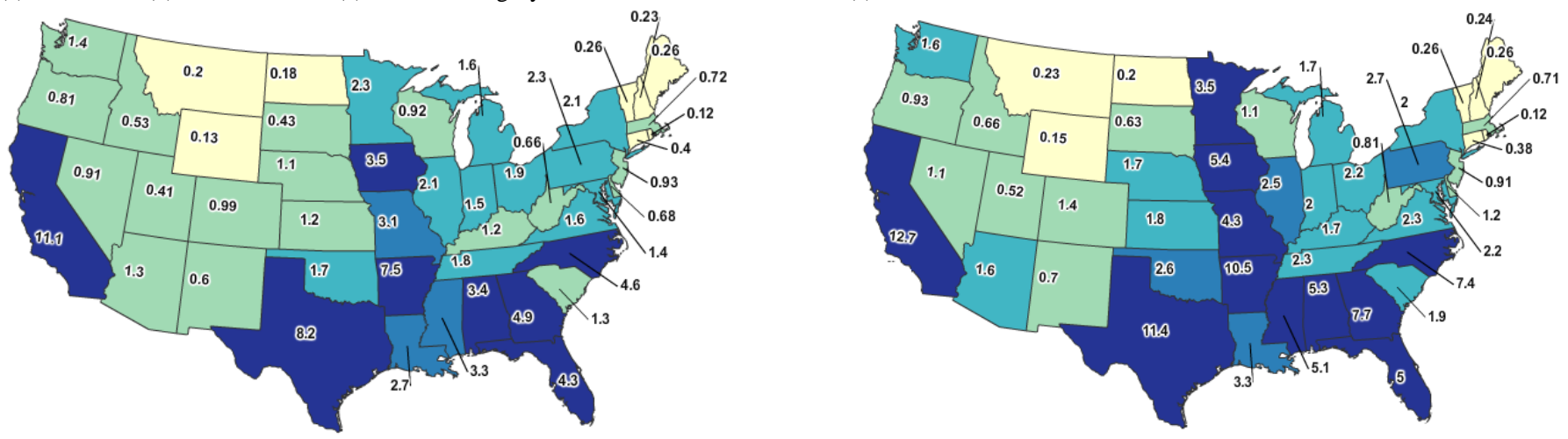

Fig. 6 Secondary feedstock at $\$ 60 /$ ton: (a) Year 2015, and (b) Year 2030
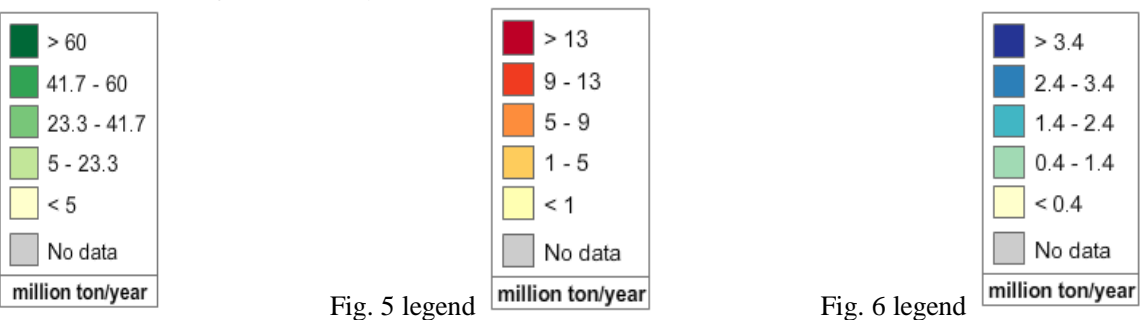
Table 2 also shows the costs involved in upgrading and operating the coal plants to co-fire biomass. For up to $10-15 \%$ co-firing, the levelized cost of electricity (LCOE) is assumed as $\$ 0.035 \mathrm{M} / \mathrm{GWh}[10]$; and depending upon the conversion efficiency of the feedstock used for co-firing (as given in the first column of Table 3), the cost per unit feed varies, as shown in Table 2.

Table 2 Emissions for feedstock production practices and co-firing investments

\begin{tabular}{c|cc:c}
\hline Feedstock & $\mathrm{CO}_{2}($ Good practices $)$ & $\mathrm{CO}_{2}$ (Worst practices $)$ & Co-firing costs \\
\hline & \multicolumn{2}{|c}{ Short ton / kiloton } & M $\$$ /kiloton \\
\hline Primary agriculture & 311.95 & 623.9 & 0.0584 \\
Forestry & 233.97 & 350.95 & 0.0626 \\
Secondary & $<-756.77$ & $>605.42$ & 0.0621 \\
\hline
\end{tabular}

Table 3 shows energy derived from biomass in a matrix format, where rows represent feedstocks and columns conversion processes to which the feedstocks are subjected. The values are estimated as a function of biomass energy content and conversion process' thermal efficiency, as shown in Eq. (1). The typical energy content in primary, forest and secondary feedstock resources are about $8000 \mathrm{BTU} / \mathrm{lb}, 8570$ $\mathrm{BTU} / \mathrm{lb}$, and $8500 \mathrm{BTU} / \mathrm{lb}$ respectively [32]. The feedstocks used for AD generally are wet, in which case their energy content for the AD process is lower: about $5470 \mathrm{BTU} / \mathrm{lb}, 5140 \mathrm{BTU} / \mathrm{lb}$, and $5000 \mathrm{BTU} / \mathrm{lb}$, respectively. The thermal efficiencies of combustion, gasification, and $\mathrm{AD}$ processes are assumed to be $28.2 \%, 35 \%$, and $28.5 \%$ respectively, and co-firing with $10 \%$ biomass is assumed to reduce the coal plant efficiency from $33 \%$ to about $32.3 \%$ [33]. The biomass thermal efficiency of gasification unit may go up to $70 \%$ with a combined cycle operation (known as biomass integrated gasification combined cycle (BIGCC)). AD plants operated with wet secondary feedstocks have a lower thermal efficiency of about $19.6 \%$ [34]. Typically, bio-refineries operate with a higher thermal efficiency of about 70-80\%, and produce about 80-90 gallon of biofuel per dry ton of biomass. Based on each resource's energy content, the bio-fuel yield will vary.

$$
\eta_{(i, j)}=h_{e k} \eta_{(j, j)} \text {, where } i=\text { fuel \& } j=\text { conversion }
$$

Table 3 Biomass conversion efficiencies (GWh/kiloton or million gallons/kiloton)

\begin{tabular}{c|ccrrc}
\hline $\begin{array}{c}\text { Conversion }(j) \\
\text { Vs. Feedstock }(i)\end{array}$ & Co-firing & AD & Gasification & Combustion & Bio-refinery (pyrolysis) \\
\hline Primary & 1.670 & 0.804 & 1.810 & 1.458 & 0.13 \\
Forestry & 1.789 & 0.942 & 1.938 & 1.562 & 0.1 \\
Secondary & 1.774 & 0.633 & 1.922 & 1.549 & 0.08 \\
\hline
\end{tabular}

\section{LONG-TERM INFRASTRUCTURE PLANNING MODEL -NETPLAN}

This section presents the mathematical formulation of NETPLAN, a long-term expansion planning model for energy and transportation infrastructure systems $[2,17,18]$, where the various biomass pathways discussed in Section III are integrated. The NETPLAN tool will be used in this paper to simulate various long-term capacity expansion scenarios, and assess the role of bio-renewables. NETPLAN in the past has been used to perform various planning studies with an intent to assess long-term cost, emissions and resilience associated with nation-wide infrastructure planning, including assessing the impact of highspeed rail (HSR) on U.S. passenger transportation [18], designing high capacity interregional transmission overlay under high renewable scenarios [19,35], designing resilient energy infrastructure against catastrophic events [36], and planning national light duty vehicle portfolio [37]. NETPLAN is written in $\mathrm{C}++$, and the code and the data are made public ${ }^{2}$.

In this model, the U.S. energy system model is divided into 13 regions following the U.S. Energy Information Administration's (EIA) National Energy Modeling System (NEMS) [38]. The generation technologies that are modeled are: nuclear, coal, coal w/ carbon capture and sequestration (CCS),

\footnotetext{
${ }^{2}$ NETPLAN code and data: https://github.com/vkris83/NETPLAN
} 
integrated gasification combined cycle (IGCC), IGCC w/CCS, natural gas combined cycle (NGCC), NGCC w/CCS, oil, combustion turbine (CT), geothermal, solar photovoltaics (PV), solar thermal (concentrated solar power (CSP)), wind, offshore wind, ocean thermal energy conversion (OTEC), tidal, hydro, integrated pyrolysis combined cycle (IPCC), biomass combustion (BC), biomass gasification (BG), and biomass anaerobic digestion (AD). Appendix section VII.A provides further details on the existing generation capacities within each of the 13 NEMS regions in the reference year (2010), and also provides details on the regional electricity demands and their growth rate. Appendix section VII.A also provides the cost and performance (including $\mathrm{CO}_{2}$ emission factors) characteristics of each of these technologies (which is used for optimizing the energy systems), and also the fuel prices assumed in this study. On the transportation side, the model includes freight and passenger transportation. The mode choices for freight transportation include diesel trucks and trains, and for passenger transportation include light duty passenger vehicles (LDVs), airplanes, and electric rails (high speed rails (HSR). The decision variables in the model for transportation sector include demand allocation (i.e., freight) via diesel trucks and diesel trains in each interstate arc for freight transportation. In the case of passenger transportation, the utilization of LDVs (gasoline cars and plug-in hybrid electric vehicles (PHEVs)), airplanes and high-speed rail (HSR) for carrying passenger demand across the various inter-state arcs and how many LDVs are required to provide intra-state vehicles demanded. Appendix section VII.B provides detailed modeling and data assumptions including information on the inter-state transportation arcs, the operational and investment data for each of these transportation mode choices (which is used for optimizing the transportation portfolio). Appendix section VII.B also provides data on the fuel price and $\mathrm{CO}_{2}$ emission factor assumptions, including biofuel options.

NETPLAN basically is a multi-period network flow linear optimization model [39] (as shown by Eqs. (2-21)), where the energy flows in all the arcs that connect supply and demand nodes are optimized. For a nodal component like generator, arc $(i, j)$ connects fuel node and generator output, signifying energy conversion; for transmission lines, arc $(i, j)$ connects energy nodes $i$ and $j$. The primary characteristics of each arc are cost of energy flow, efficiency, minimum and maximum capacity. It is to be noted that while energy flows are optimized in the arcs that carry energy (fuel and electricity), passengers and vehicle movements are optimized in the transportation arcs. The objective function is to minimize the operational and investment costs in energy and transportation sectors over the entire planning horizon (from years 2010-2049), as given in Eq. (2). The objective function also consists of $s=1 \ldots n$ variables representing $n$ segments of any resource's supply curve, associated with their respective prices. The optimization is subject to constraint Eqs. (3-21) imposed at every time period $t$, where Eqs. (3-9) model energy network related constraints, including biomass supply curves in Eqs. (7-8) and co-firing in Eq. (9). Equations (1014) model relationships related to regional LDV allocations, and Eqs. (15-20) model interstate transportation related constraints. Constraint Eq. (15) models the demand imposed by energy sector on the transportation sector, and constraint Eq. (21) models demand imposed by transportation sector on the energy sector; thereby capturing their interdependencies. Each of these constraints will be explained further.

\section{$\underline{\text { Minimize }}$}

$\sum_{t} \sum_{(i, j)}(1+r)^{-t}\left(\operatorname{CostOp}_{(i, j)}(t) \boldsymbol{e}_{(i, j)}(t)+\sum_{s=1}^{n} \operatorname{CostOp}(i, j),(t) e_{(i, j)}^{s}(t)\right)+\sum_{t} \sum_{(x, y, k, m)}(1+r)^{-t}\left(\operatorname{CostOp}_{(i, j)}^{p}(t) p_{(i, j)}(t)+\operatorname{Cost} O p_{(x, y, k, m)}(t) f_{(x, y, k, m)}(t)\right)+$

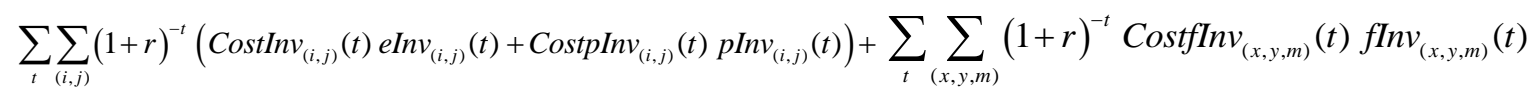

\section{Subject to}

Equations modeling nodal energy balance 
$\sum_{i} \eta_{(i, j)}(t) e_{(i, j)}(t)-\sum_{j} e_{(j, k)}(t)=d^{e}{ }_{j}(t)+d^{e T}(t)$

$0 \leq l b e_{(i, j)}(t) \leq e_{(i, j)}(t) \leq c a p_{-} e_{(i, j)}(t)$

$c a p_{-} e_{(i, j)}(t)=u b e_{(i, j)}(t)+\sum_{z=i n v . s t a r t}^{t} e I n v_{(i, j)}(z) I\left(t-z \leq l i f e_{(i, j)}\right)$

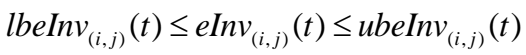

Equations modeling supply curve

$7 \quad \sum_{s=1}^{n} e_{(i, j)}^{s}(t)=e_{(i, j)}(t)$

$0 \leq l b e_{(i, j)}(t) \leq e_{(i, j)}^{s}(t) \leq\left(u b e_{(i, j)}^{s}(t)-u b e_{(i, j)}^{s-1}(t)\right) \leq c a p_{-} e_{(i, j)}(t), s=1, \ldots n$

Equations modeling biomass co-firing with coal

$\sum_{i}^{\text {biomasss }} e_{(i, j)}(t) \leq b_{\text {coffre }} \sum_{i}^{\text {coal }} e_{(i, j)}(t), i \in 1 T, 2 T \ldots \& j \in E C$

Equations modeling regional LDVs (specific case of eq. (3))

$\sum_{i} p_{(i, j)}(t)=d_{j}^{p T}(t)$

$\sum_{i} \eta_{(i, j)}(t) e_{(i, j)}(t)=p_{(i, j)}(t)$

$0 \leq p_{(i, j)}(t) \leq c a p_{-} p_{(i, j)}(t)$

$\operatorname{cap}_{-} p_{(i, j)}(t)=u b p_{(i, j)}(t)+\sum_{z=\text { inv.start }}^{t} \operatorname{pInv}_{(i, j)}(z) I\left(t-z \leq\right.$ plife $\left._{(i, j)}\right)$

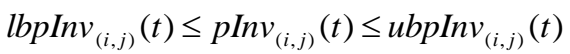

Equations modeling interstate mode share

$\sum_{m, k=e k,\{x, y \subset j\}} \eta_{(x, y, k, m)}(t) f_{(x, y, k, m)}(t)=\left(h_{e k} \eta_{(i, i)}\right)^{-1} e_{(i, j)}(t)$, where $i=$ conversion $\& j=$ demand

$$
\sum_{m, k=f k} \eta_{(i, j, k, m)}(t) f_{(x, y, k, m)}(t)=d^{T}(x, y, f k)(t)
$$

$\sum_{m, k=p} \eta_{(x, y, k, m)}(t) f_{(x, y, k, m)}(t)=d^{T}{ }_{(x, y, p)}(t)$

$0 \leq \sum_{k} f_{(x, y, k, m)}(t) \leq c a p_{-} f_{(x, y, m)}(t)$

cap__ $f_{(x, y, m)}(t)=u b f_{(x, y, m)}(t)+\sum_{z=i n v, s t a r t}^{t} f I n v_{(x, y, m)}(z) I\left(t-z \leq f l i f e_{(x, y, m)}\right)$

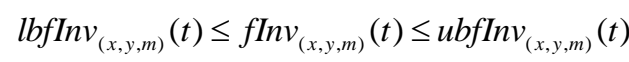

$d^{e T}{ }_{j}(t)=f u e l C_{m}(t)\left\{\sum_{i} l^{p}{ }_{(i, j)}(t) p_{(i, j)}(t)+l_{(x, y)}(t) \alpha^{j}{ }_{x, y}\left(\sum_{k} f_{(x \subset j, y, k, m)}(t)+\sum_{k} f_{(y, x \in j, k, m)}(t)\right)\right\}$

At each node the energy inflows and outflows must be such that the nodal demand must be met, as in Eq. (3). The arc efficiency parameter in Eq. (3) models energy conversion \& transmission efficiencies, and capacity factor. E.g., fuel to generation output conversion efficiency, generation capacity factor over a year, transmission and pipeline losses. When $i=j$, it is a particular component's thermal efficiency. The energy demanded may be electricity, petroleum or natural gas depending upon the sub-system of the energy system where the node $j$ is situated. In this national electric network model at the inter-regional scale, the demand nodes represent aggregated regional demand and the transmission lines that connect these electricity demand nodes represent aggregated inter-regional transmission. DC power flow 
arcs (generation, gas pipelines, and bi-directional transmission) is bound within a lower limit and the total capacity, as expressed in Eq. (4). The total arc capacity at any period $t$ is the sum of the existing maximum infrastructure capacity at that period $\left(u b e_{(i . j)}(t)\right)$ and new investments done at every period until $t$ (subject to their life), as shown in Eq. (5). The function $I\left(t-z \leq\right.$ life $\left._{(i, j)}\right)$ equals to 0 if at time $t$ the investment made at time $z$ has exhausted its life, and equal to 1 otherwise. The capacity investments are bound within limits, as in Eq. (6). The model also accounts for renewable generation's capacity credit to supply peak demand in every region during various time intervals (not shown in the equations). The gas storage model imposes inter-period constraints, where the stored energy at the end of period $t$ is the sum of stored energy until previous period $(t-1)$, plus the injections and less the withdrawals at period $t$ (also not shown in the equations).

For resources, whose quantities are modeled using a supply curve, constraint Eqs. (7-8) are used. The supply curve is a monotonically increasing piecewise quantity vs. price curve. The $n$ segments of the supply curve for the resource flowing through $\operatorname{arc} e_{(i, j)}$ is modeled using a set of $s=1 \ldots n$ parallel $\operatorname{arcs} e_{(i, j)}^{s}$, such that the sum of commodity flows in the $n$ segments equals the flow in the arc $e_{(i, j)}$, as modeled by Eq. (7). The upper bound of each of these parallel arc variables is equal to the length of that particular segment, as computed and expressed in Eq. (8). Equation (9) models the bound on the total biomass resources that will be co-fired with coal in the coal-fired units, EC. As shown in Fig. 2, while 1T to EC denotes supply of coal to the coal-fired unit, $2 \mathrm{~T}$ to EC denotes supply of a particular variety of biomass for co-firing. Therefore, the sum of all the biomass resources fed to the coal-fired unit should be less than or equal to a certain proportion, $b_{\text {cofire }}$, of the sum of all the coal commodities fed into that unit. For $10 \%$ co-firing, $b_{c o f i r e}$ is $0.1111(10: 90)$.

The demand for LDVs within a region $j$ is shared by competing LDVs as shown in Eq. (10), based on their investment cost (accounted in Eq. (2)) and operational cost \& efficiency (fuel conversion) (accounted in Eq. (2) \& Eq. (11)). Equations (10-11) are special cases of nodal balance Eq. (3); where the demand in this case is the nodal (denoting U.S. regional) LDV demand shown in Eq. (10), which in turn imposes a demand on energy consumption as per Eq. (11) using a particular LDV's fuel conversion efficiency (a function of LDV's miles per gallon). Each LDV fleet is subject to the maximum available vehicles as per Eq. (12), and is allowed to expand as per Eqs. (13-14).

Equation (15) models demand imposed on transportation sector to transport energy related freight commodities (i.e., coal and biomass) across the states $x$ and $y$, which will be allocated among the appropriate mode of transportation (diesel trains and trucks). Equations (16) and (17) are similar to Eq. (15), provided they are modeling the transportation mode allocation for transporting regular freight commodities (through diesel trains and trucks) and passengers (through air, HSR, and LDVs) across the states respectively. The efficiency terms in these equations Eqs. (15-17) represent the demand sharing capability of a particular mode across a particular interstate route, which is a function of its freight or passenger carrying capacity and trip frequency across that interstate $\operatorname{arc}(x, y)$ within each optimization interval. Equation (18) constrains the interstate transportation based on the available fleets, subject to fleet size expansion as modeled by Eqs. (19-20). Equation (21) models the relation that governs the demand imposed on the energy sector by the transportation sector, as accounted in the nodal balance Eq. (3). Equation (21) accounts for the energy needed by regional LDVs (where each LDV $i$ in region $j$ travels a mean distance $l_{(i, j)}^{p}$ ) and interstate fleets (that travel across interstate links of distance $l_{(x, y)}$ ). It is also assumed that a proportion $\alpha_{x, y}^{j}$ of energy for bi-directional interstate transportation across states $(x, y)$ comes from region $j$ and the rest $\left(\alpha_{x, y}^{i}=1-\alpha_{x, y}^{j}\right)$ from region $i$ (when state $x$ belongs to the region $j$ and state $y$ belongs to the region $i$ ). If both states $x$ and $y$ belong to the region $j$, then all the energy is supplied from $j$. 
This section presents the numerical results of two planning cases: A) considering only the energy sector and its interdependencies with the freight transportation system (for coal and biomass transportation), and B) considering energy sector together with freight and passenger transportation sectors, which includes regional LDVs and interstate freight \& passenger transportation. The optimization is performed over a 40year planning horizon (2010-2049). The infrastructure investment decisions are taken at yearly time steps. The operations are optimized at different time periods in different sub-systems that were presented in Section III.B. The optimization time period for various subsystems within the energy network are as follows: yearly time steps for the coal subsystem (consisting of production and transportation), yearly time steps for the biomass subsystem (consisting of feedstock production, transportation and bio-fuel production at bio-refineries), monthly time steps for the natural gas subsystem (consisting of production, transshipment and storage); and monthly time steps for the electric subsystem (consisting of generation including bio-power conversion facilities, transmission and load). The portfolios for regional LDVs, interstate freight and passenger transportation are optimized at yearly time steps. Yearly discount and inflation rates applied to the cost information within the optimization are $7 \%$ and $2 \%$, respectively. The model uses the salvage value approach to mitigate the end effects due to simulation truncation [40]. The model formulation and data input/output are implemented using $\mathrm{C}++$, while the optimization is solved using CPLEX in a server with a $1.6 \mathrm{GHz}$ processor and $47 \mathrm{~GB}$ of RAM. The 40-year energy and transportation cost minimization LP model has 748,680 constraints and 889,160 variables, and the average simulation time is about 50 minutes.

\section{A. Energy sector planning}

Here, we model only the interdependencies between the energy and the freight transportation systems, and the decision variables include the types, locations, and amounts of power generation and interstate freight transportation technologies. Four different scenarios were simulated.

Scenario 1 (Reference): All data assumptions mentioned in previous sections corresponding to a business-as-usual estimation of technology cost and performances hold true, including use of the good farming practices (see Table 2 ) for emissions and high primary agricultural feedstock yields ( $4 \%$ above the baseline, see Table 1).

Scenario $2\left(\mathrm{CO}_{2}\right.$ constraint): In addition to the reference case assumptions, a yearly $\mathrm{CO}_{2}$ emission constraint has been imposed such that in year 5, emissions are $90 \%$ of the year 5 emissions in the reference case, and thereafter there is a yearly emission decrease at $2 \%$ per year till year 40 .

Scenario $3\left(\mathrm{CO}_{2}+\right.$ no bio-diesel): In addition to the scenario 2 assumptions, the biomass is used only for bio-power and not for bio-diesel production.

Scenario 3a (BIGCC): This is the same as Scenario 3, except here we employ the assumption that gasification occurs at higher efficiencies with BIGCC units.

Figure 7 shows the bio-power capacity penetration for the scenarios 1-3a, where BC, BG (BIGCC in 3a), $\mathrm{AD}$, and IPCC together form the bio-power generation. It is seen that under scenarios driven by carbon emissions reduction targets, bio-power plays a significant role and reaches a penetration level of $2-5 \%$ around 2030 and $12-16 \%$ at 2050. This is in line with NREL $80 \%$ renewable electricity future forecasts in [15]. Figure 8 shows the 40-year generation portfolio and $\mathrm{CO}_{2}$ emissions for scenarios 1 and 3a, again revealing the increasing presence of bio-power resources in the portfolio mix under carbon constrained scenarios along with the increase in renewables (mainly inland wind with $\sim 31 \%$ capacity penetration in 2050) and conventional technologies retrofitted with CCS. It should be noted that the generation portfolio shown in Fig. 8 may differ in the years after 2014 because of the rapidly decreasing solar PV costs, which may enable higher penetration of solar PV resources in the portfolio. Consequently the increase in solar PV penetration will primarily replace other expensive clean energy technologies shown in Fig. 8, such as geothermal, NGCC-CCS, IGCC, and IGCC-CCS [20]. Except scenario 3, co-firing biomass with coal was 
not preferred in any of the scenarios. In scenario 3, during 2014-2015 (the years when $\mathrm{CO}_{2}$ emission reduction target decreases steeply) about 22 Million tons of biomass, mainly comprised of forestry and secondary feedstock, was used for co-firing in the Eastern U.S. states (PA, MD, FL, NC, AL, MS and GA). This is in line with realistic observations where Eastern states are heavily populated with highly emitting 5 coal units [41].
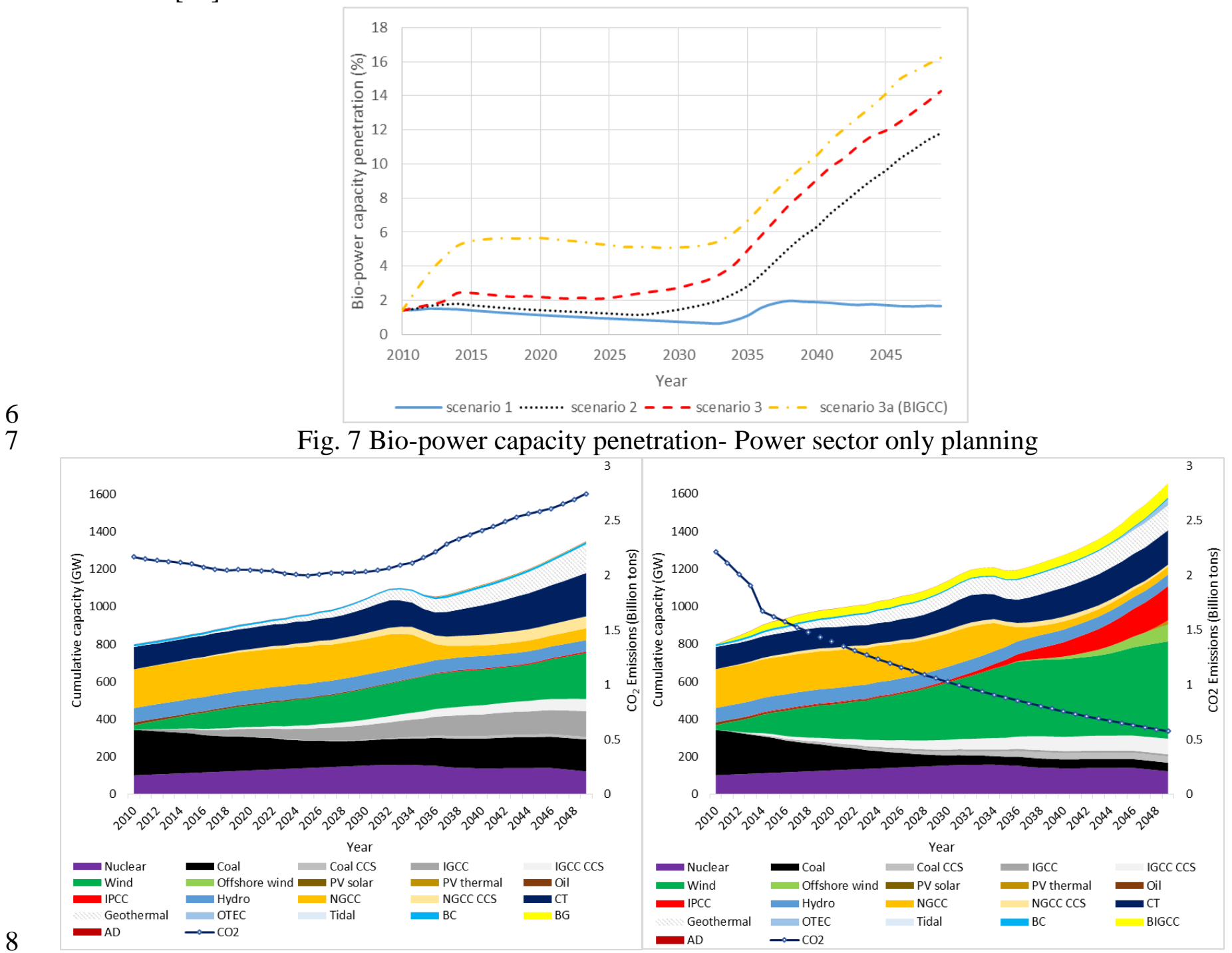

Fig. 8 Generation portfolio- cumulative yearly capacity for scenario 1 (left side) and scenario 3a with

BIGCC (right side)

Table 4 provides a summary of the four scenarios using the 40 -year cost and emission results. The emissions are provided for each sector, i.e., emissions from power generation, freight transportation, biomass (i.e., production, transportation and conversion), and all feeds production (coal, gas, oil and biomass), respectively. The final column provides the percentage of national biomass feedstock potential being used for bio-power and bio-diesel, respectively. The least cost generation portfolio comes at a total long-term cost of 3.99 Trillion USD (2010\$), with a long-term $\mathrm{CO}_{2}$ emissions of 88.7 Billion short tons. About 72 Billion short tons come from combusting fuel for power generation, while the remaining comes from fuel production and transportation (freight). Of the 98 Billion tons biomass feedstock potential over the 40 years, only about $2.59 \%$ gets utilized for power production. With a $\mathrm{CO}_{2}$ constraint in scenario 2 , national emissions decreases by about $49 \%$ at an additional long-term cost of 170 Billion USD (totaling 4.16 Trillion USD) mostly due to investments in technologies furthering renewable energy. Bio-power contributes positively in this scenario, as seen from the increase of biomass feedstock usage to $2.83 \%$. 
1 Feedstock use for biodiesel decreases as seen from the decrease in the emissions from biomass feedstock

\begin{tabular}{|c|c|c|c|c|c|c|c|}
\hline Scenario & 40-year Cost & \multicolumn{5}{|c|}{ 40-year $\mathrm{CO}_{2}$ Emissions (Billion short tons) } & 40-yr Feedstock (\%) \\
\hline & (Trillion \$) & Total & Power & Freight & Biomass & All feeds & $(100 \%=98$ B-ton $)$ \\
\hline 1. Power sector - Reference & 3.99 & 88.7 & 72.0 & 0.164 & 0.2750 & 16.6 & 2.59 \\
\hline 2. Power sector $-\mathrm{CO}_{2}$ constraint & 4.16 & 45.3 & 31.7 & 0.161 & 0.0236 & 13.5 & 2.83 \\
\hline 3. Power sector $-\mathrm{CO}_{2}$ constraint + no bio-diesel & 4.46 & 45.5 & 29.5 & 2.70 & 0.00004 & 13.3 & 1.10 \\
\hline 4. Power sector $-\mathrm{CO}_{2}$ constraint + no bio-diesel + BIGCC & 4.43 & 45.4 & 29.5 & 2.69 & 0.00004 & 13.2 & 3.57 \\
\hline
\end{tabular}

\section{B. Energy and transportation sectors planning}

Three additional scenarios (scenarios 4-6) were simulated for national energy and transportation freight transportation and all feeds emissions due to the decrease in coal usage). Deliberately decreasing the use of feedstock for biodiesel and diverting them to bio-power production, per scenario 3, decreases the emissions in power and fuel production sectors, but does not prove beneficial since it increases both the total emissions (due to emissions from freight transportation) and the total long-term costs by about 300 Billion USD. Another interesting phenomenon observed in scenario 3 results is, from a biomass seller's perspective, though feedstock use for biodiesel is restricted to null, there is no increase in feedstock use for bio-power as doing so is not competitive in the power sector when feedstock prices reach $\$ 40-50 /$ dryton (most of the forestry resources are not economically available for power generation), beyond which bio-power becomes too expensive (unless a more efficient technology such as BIGCC attracts more feedstock as in scenario 3a). A similar conclusion is drawn by the researchers at the National Renewable Energy Laboratory (NREL) with respect to biomass' usage for bio-power, wherein biomass combustion retrofitted with CCS is cited as another potential technology that could promote bio-power penetration under carbon constraint scenarios [42].

Table 4 Results summary: Cost, Emissions and Feedstock for bio-power \& bio-diesel planning. Each of these differ from Scenarios 1-3 in that decision variables not only included the types, locations, and amounts of power generation and interstate freight transportation technologies, but also the types and amounts of passenger transportation technologies (regional LDVs and interstate) and the interdependencies between the sectors [18]. Scenarios 4 and 5 have similar assumptions as described for scenarios 1 and 2, respectively. Therefore Scenario 4 can be considered as the reference scenario for the energy and transportation sector planning. Scenario 6 is $\mathrm{CO}_{2}$ constrained similar to scenario 5, with an additional assumption that the petroleum price increases by $5 \%$ every year (which impacts diesel, gasoline and jet fuel prices). This scenario is simulated as a proxy to assess the fuel mix and the cost impacts under the need to reduce the petroleum dependence. In all the above scenarios, biofuels is assumed not to be used for aviation purposes. In addition to these basic scenarios, a few other scenarios are simulated to assess sensitivities, namely "bio-aviation" (where aviation biofuels are also considered), "no biomass" (where biomass is assumed to be unavailable, to enable identification of the role that biomass plays in a low carbon energy and transportation portfolio), "baseline yield" (primary feedstock production set to the baseline yield per Table 1), and "worst practices" (feedstock production and processing assumed to occur under worst practices per Table 2).

Figure 9 shows biomass feedstock usage under scenarios 3a-6 (including scenario 6 with biofuel for aviation) and the potential (both under baseline and high yield assumptions for primary feedstock) from 2010-2049. With the inclusion of passenger transportation in the model and the corresponding demand for ethanol, the biomass usage has increased tremendously as seen in Fig. 9. Biomass feedstock use for passenger transportation in scenarios 4-6 proves competitive even up to higher feedstock prices in comparison to its use in the power-sector alone per scenario 3a, with the demand for feedstock growing as high as the potential in the near future and remaining around 1.6 Billion tons until 2050 (about 50-65\% of the estimated potential in 2050). 


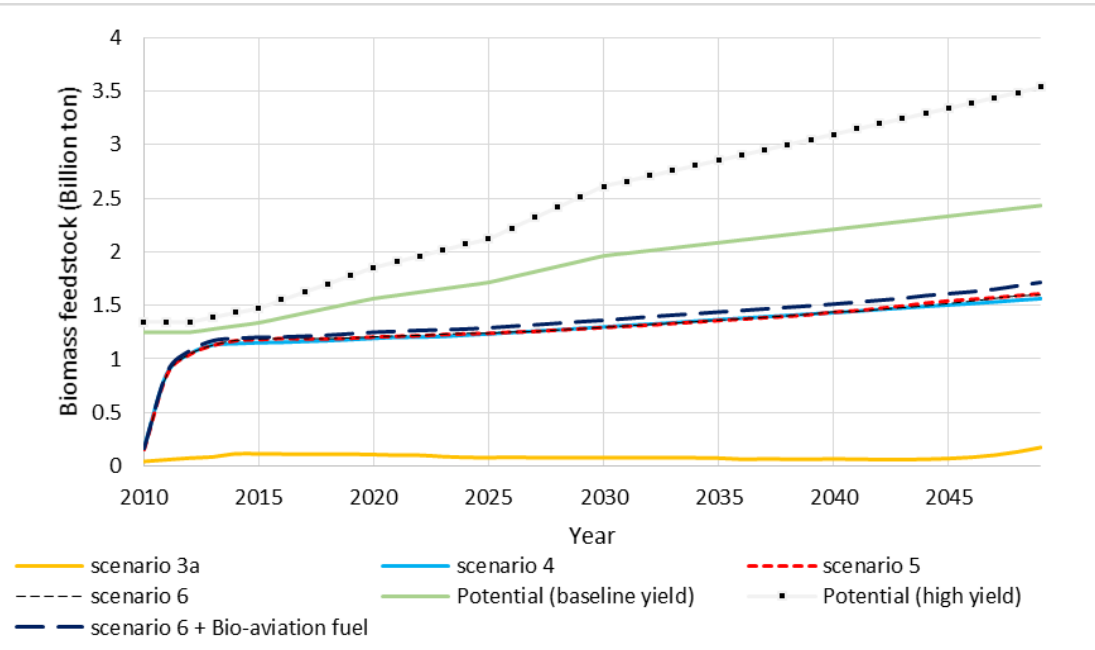

Fig. 9 Biomass feedstock usage- potential vs. scenarios (3a-6)

This is also observed in Table 5, which shows the 40-year fuel consumption for transportation and the composition in different scenarios. In scenario 4, even without a carbon constraint, biofuels prove to be a cost-effective option for transportation fuels. As seen in Table 6, which provides the 40-year transportation fleet for these scenarios (LDVs in billion vehicles and interstate travels in trillion passenger miles), in scenario 4, passengers are primarily served by conventional LDVs and airplanes. With a $\mathrm{CO}_{2}$ constraint in scenario 5, biofuels still supply fuel needs for interstate freight and LDVs; however there is decrease in air travels and increase in HSR travels, with a commensurate increase in electricity consumption; this tendency is further accentuated by the petroleum price-hike of scenario 6 . While electrification of passenger transportation definitely reduces the emissions in this sector, it further drives the need for renewable energy in the power sector to ensure an overall emission benefit [18]. On the other hand, due to the availability of biofuels, LDV and interstate fuel composition changes very little as emission targets or petroleum price-hikes are imposed, as indicated in Table 5. Table 5 also summarizes the "scenario $6+$ bioaviation" scenario, when biofuels find increasing usage for aviation purposes (assuming the costs are comparable to ethanol). We find, in Table 6, the passenger transportation mode shares again become dominated by conventional LDVs and air travels.

Table 5 Transportation fuel composition (40-year total consumption)

\begin{tabular}{c|cccc}
\hline Fuel (Billion Gallons) & Scenario 4 (reference) & Scenario 5 $\left(\mathrm{CO}_{2}\right)$ & Scenario 6 $\left(\mathrm{CO}_{2}+\right.$ petrol) & Scenario 6 + Bio-aviation \\
\hline Diesel & 0.81 & 0.81 & 0.81 & 0.81 \\
Bio-diesel & 222.81 & 198.33 & 198.47 & 208.46 \\
Ethanol & 6159.53 & 6160.69 & 6158.34 & 6160.67 \\
Bio-aviation & - & - & - & 312.31 \\
Gasoline & 159.15 & 159.13 & 159.13 & 159.13 \\
Gas (BCF) & 118.84 & 0 & 1.39 & 1.40 \\
Jetfuel & 316.72 & 276.72 & 173.99 & 8.36 \\
Electricity (TWh) & 108.62 & 342.47 & 954.32 & 85.50 \\
\hline
\end{tabular}

Table 6 Passenger transportation: 40-year LDV and interstate mode shares

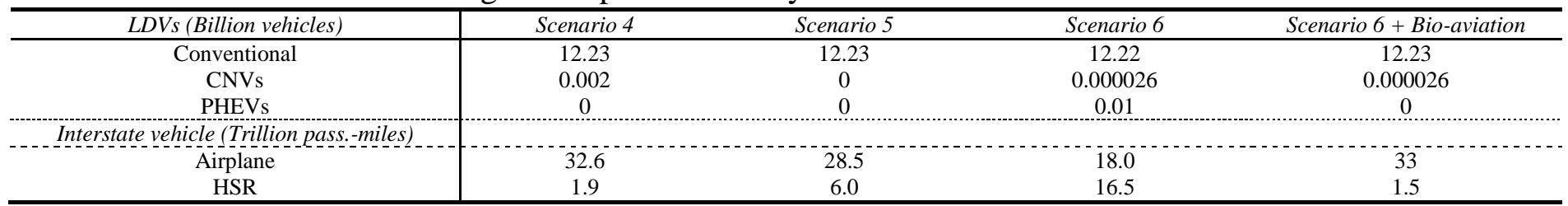

Table 7 provides a summary of the results for energy and transportation planning done under the three scenarios 4-6, and some selected sensitivity scenarios. This table additionally provides the emissions in the passenger transportation sector. The least cost 40-year national energy and transportation portfolio is found to be about 28.1 Trillion USD (2010\$) in scenario 4, with a total long-term $\mathrm{CO}_{2}$ emissions of 103 Billion 
1 short tons, more than $60 \%$ of which is from power generation. When aviation biofuel is considered, the estimated long-term costs and emissions decrease by about 300 Billion USD and 3.4 Billion short tons, respectively, primarily due to the decrease in passenger transportation fuel costs and in $\mathrm{CO}_{2}$ emissions. There is not much impact in long-term costs and emissions when a baseline yield is assumed for primary feedstock; however if the feedstock comes with poor practices during production and processing stages, it increases emissions as seen in Table 7 under scenario 4 sensitivity "reference + baseline yield + worst case practices", where the emissions from the biomass pathways and freight transportation sector increases leading to an increase of up to 20 Billion short tons across the nation over the 40 -year period). The scenario 4 sensitivity "reference + no biomass" quantitatively shows the important place bio-renewables should occupy in the national strategy towards a low carbon economy, as without biomass, the nation could incur 7 Trillion additional USD and 65 Billion short tons of $\mathrm{CO}_{2}$ over the 40-years to meet the electric and transportation demands. This is primarily due to the absence of biofuels for passenger transportation and to some degree freight transportation, with little influence from the power sector.

Under scenarios with carbon reduction targets as in the case of scenario 5, the importance of the role of bio-renewables is heightened. As seen from Table 7, with bio-renewables in the portfolio the total $\mathrm{CO}_{2}$ emission reduction of about $40 \%$ over the 40 -year horizon is achieved at an additional long-term cost of 300 Billion USD. The bulk of the emissions reduction is due to reduction in conventional coal generation (and a commensurate decrease in coal movements, and hence in freight and feed emissions), and an increase in renewable generation such as wind, geothermal, and CCS-retrofitted technologies. Furthermore, without bio-renewables in the planning options, only about $10 \%$ reduction is achieved in 21 long-term $\mathrm{CO}_{2}$ emissions at an additional cost of about 10 Trillion USD. In such a case, to meet emissions 22 targets, it becomes essential to build a low-carbon power sector to supply the additional electricity for powering the transportation sector (PHEVs and HSR). The scenario 6 and its sensitivity without biorenewables is designed to emphasize the role of bio-renewables in rendering the energy and transportation infrastructure resilient to petroleum price-hike events. Again, in such circumstances, the portfolio has to heavily depend on sustainable and often expensive means of electrification, which may become several trillion USD more cost-effective with the large-scale availability of bio-renewables, particularly biofuels.

\begin{tabular}{|c|c|c|c|c|c|c|c|}
\hline \multirow[t]{2}{*}{ Scenario } & 40-year Cost & \multicolumn{6}{|c|}{ 40-year $\mathrm{CO}_{2}$ Emissions (Billion short tons) } \\
\hline & (Trillion \$) & Total & Power & Freight & Passenger & Biomass & All feeds \\
\hline \multicolumn{8}{|l|}{ Scenario 4 and sensitivities } \\
\hline Reference (high yield) & 28.1 & 103 & 62.6 & 0.184 & 11.4 & 19.1 & 28.5 \\
\hline Reference + aviation biofuel & 27.8 & 99.6 & 63.1 & 0.186 & 7.02 & 19.8 & 29.3 \\
\hline Reference + baseline yield & 28.2 & 102 & 62.7 & 0.184 & 11.4 & 18.1 & 27.5 \\
\hline Reference + baseline yield + worst case practices & 28.2 & 122 & 62.7 & 0.303 & 14.7 & 38.6 & 44.7 \\
\hline Reference + no biomass & 35.1 & 168 & 62.1 & 2.9 & 88.9 & 0 & 14.4 \\
\hline \multicolumn{8}{|l|}{$\begin{array}{l}\text { Scenario } 5 \text { and sensitivities } \\
\end{array}$} \\
\hline $\mathrm{CO}_{2}$ constraint & 28.4 & 61.9 & 26.0 & 0.165 & 10.8 & 17.8 & 24.9 \\
\hline $\mathrm{CO}_{2}$ constraint + no biomass & 38.2 & 90.9 & 11.4 & 2.53 & 65.8 & 0 & 11.2 \\
\hline \multicolumn{8}{|l|}{ Scenario 6 and sensitivities } \\
\hline $\mathrm{CO}_{2}$ constraint + petroleum price-hike & 28.8 & 61.9 & 26.9 & 0.166 & 9.37 & 18.1 & 25.4 \\
\hline $\mathrm{CO}_{2}$ constraint + petroleum price-hike + no biomass & 48.2 & 90.8 & 19.8 & 2.57 & 56.3 & 0 & 12.1 \\
\hline
\end{tabular}

Figure 10, on the secondary axis, shows the total nation-wide cumulative bio-refinery capacities from scenario 6 at 2010, 2014, 2020, 2030, 2040, and 2049. It is estimated to reach about 200 Billion Gallons

33 Year (BGY) at 2050 from a 2010 capacity of about 15 BGY. Figure 10, on the primary axis, shows the

34 bio-refinery capacities in each of the 13 NEMS regions. These NEMS regions and the states that fall within 35 each region are shown on the US map in Figure 11. It is seen from Fig. 10 that in 2010, the bulk of bio36 refinery capacities are located in the mid-west region MAPP, and some in MAIN, where the primary 37 agriculture resources are abundantly available as seen from resource map of Fig. 4. However, over the 4038 year planning horizon, the capacities in MAPP and MAIN grow very little. On the other hand, some of the 
Eastern regions (ECAR, STV, SPP), ERCOT and CNV where there is little 2010 capacity sees a very high growth in bio-refinery capacities. This is due to the fact that it is in these regions along the coasts (Eastern states, CA and TX) where there is high population and economic activities needing increasing demands of power and transportation. Figure 11 shows the inter-state biomass feedstock movement via freight transportation (only movements exceeding 300 Million tons over 40 years are illustrated), which again reveals that after meeting the local energy demands in the Mid-west, the abundantly available primary feedstock in the Mid-west could be moved to East, TX and CA. From another perspective, this also indicates that alternatively, bio-refinery capacities could be built in the Mid-west and the biofuels may be moved to these load centers via trucks or pipelines which are not exclusively modeled in this paper. This would thereby avoid or reduce the interstate transportation of feedstock which in some cases may prove to be more expensive than transporting the biofuels if the former occupies more volume. The focus of this paper has not been to exclusively address this question of optimal bio-refinery siting, but rather to estimate capacities of regional bio-refineries, interpreted to be the amount of biofuel capacity demanded at each region, irrespective of where the refinery is located. The information from this model may be fed into a more granular model with higher regional resolution to optimize the siting of bio-refineries.

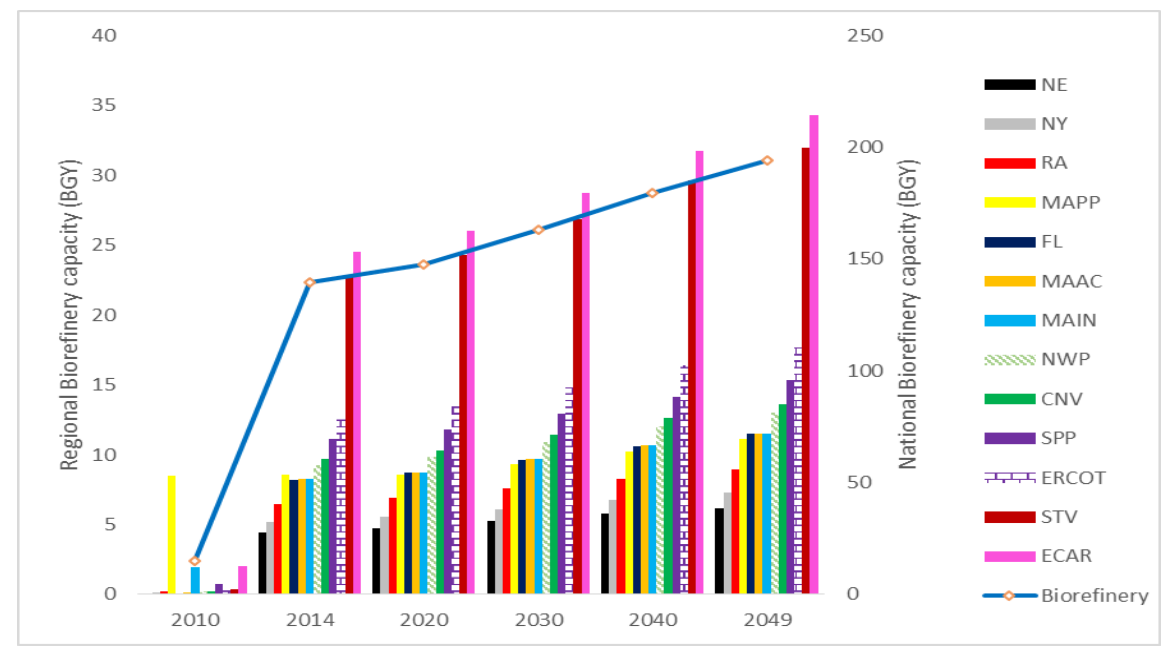

Fig. 10 Regional and national bio-refinery capacity - scenario 6

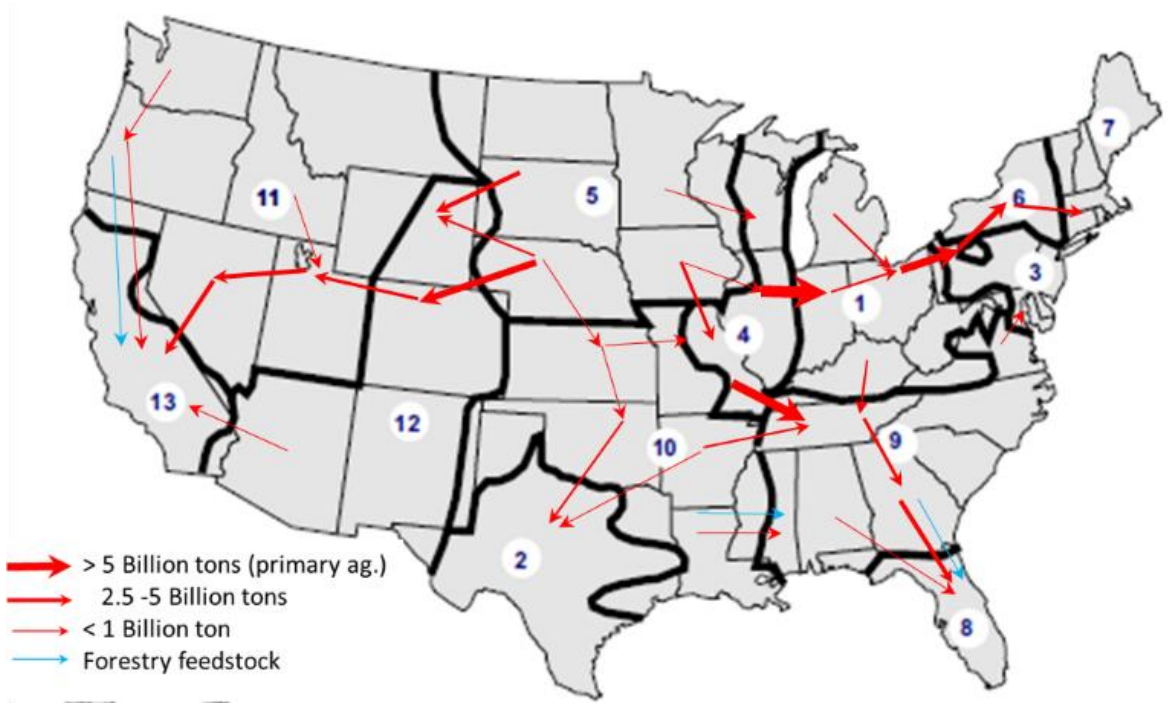

NEMS regions: 1- ECAR, 2- ERCOT, 3- MAAC, 4- MAIN, 5- MAPP, 6- NY, 7- NE, 8- FL, 9- STV, 10- SPP, 11- NWP, 12- RA, 13- CNV

Fig. 11 Interstate biomass transportation - scenario 6 (feedstock transportation, if plant sited near energy demand locations; or biofuel transportation, if plant sited near feedstock source) 


\section{CONCLUSIONS}

This paper investigated the role of bio-renewables in the long-term national energy and transportation portfolio planning towards low carbon economy. The paper described the multiple biomass pathways from feedstock production to bio-renewable energy considering both energy and transportation sector end-use, and it presented a biomass integrated long-term infrastructure planning model for the U.S. The feedstock availability and cost were characterized by geographical region across the nation for the years 2010-2050 using feedstock supply curves developed based on the DOE's billion ton update data.

Two different case studies, one modeling the energy sector only and the other modeling both the energy and the transportation sectors in an integrated fashion, were performed for different scenarios including ones with $\mathrm{CO}_{2}$ emission reduction targets. In the power-sector only model, though bio-power provides a definite means of reducing emissions, its economic viability suffers at feedstock prices more than \$40-50/dry-ton, beyond which combusting biomass loses its economic edge over coal and gas fired plants. The planning model identifies bulk power capacities that are cost-effective over the long-term; cofiring opportunities, because of their higher costs, do not have significant presence in the solutions. Biomass integrated gasification combined cycle (BIGCC) plants, if it matures enough to achieve improved efficiency relative to existing estimates, is seen as a viable option to increase bio-power penetration. Under scenarios driven by carbon emissions reduction targets, bio-power plays a significant role and reaches a penetration level of 2-5\% around 2030 and $12-16 \%$ at 2050.

On the other hand, biomass feedstock even at higher costs is competitive for biofuel production, specifically for passenger transportation fuel demand imposed by regional LDVs (ethanol) and interstate air travels (aviation biofuel). In addition, bio-diesel is attractive for transporting interstate freight, coal and feedstock transportation from the Mid-west for bio-refinery locations near the load centers in the East, TX and CA. The estimated feedstock availability over the long-term may serve well for powering a nationwide bio-refinery capacity of about 150 Billion Gallons Year (BGY) (or approx. $560^{*} 10^{9}$ liter per year) around 2020s, and about 200 (BGY) (or approx. $750^{*} 10^{9}$ liter per year) by 2050. Bio-renewables can offer significant long-term cost savings, especially under scenarios driven by carbon emissions reduction targets and reduction in the dependence on imported petroleum. For the 40 year period examined, the presence of bio-renewables in the portfolio enables up to a 10 Trillion USD (2010\$) savings in infrastructure operational and investments costs when reducing $\mathrm{CO}_{2}$ emissions by $40 \%$, assuming clean/best biomass production and production practices. Meeting emissions targets without bio-renewable deployment requires passenger transportation electrification, which in turn may impose high investment costs and heavy use of renewables in the power sector. The overriding conclusion of the work reported in this paper is that bio-renewables should play a significant role in transforming the U.S. energy and transportation sectors so that they can meet the low-carbon emissions targets likely to be set forth in the near future.

VII. APPENDIX

The 40-year energy and transportation infrastructure planning addressed in this paper for the U.S., considered a reference future scenario where the costs and technology performances are based on today's business-as-usual estimations, without projecting any particular trajectories for technology maturity (e.g, solar PV etc.); except for the characterization of nation-wide biomass feedstock potential which was discussed in Section III.C. The following two appendix sections provide details on energy and transportation sectors modeling assumptions.

\section{A. Energy sector modeling and data assumptions}

As mentioned in Section IV, the U.S. energy system is modeled by dividing the nation into 13 regions; as originally developed by the U.S. Department of Energy's (DOE) EIA for NEMS.

Demand and existing generation capacities: Table 8 provides the average and peak electricity demands, and the existing generation capacities within each of these 13 regions (which retire gradually as 
1 the planning evolves) in the reference year (2010). Currently, biomass combustors (BC) and anaerobic 2 digesters (AD) are prevailing pathways for biopower production [43]. Natural gas is primarily being used 3 for power generation and other non-power uses in residences, industries and businesses such as heating. In 4 most states, about $35 \%$ of the gas is used for power, with the remaining for non-power purposes; with very 5 few exceptions (such as Arizona and Florida) where the proportions are reversed [44]. On an average only 6 about $0.1 \%$ of the gas is used for transportation purposes in all states. So the model inputs the cumulative 7 non-power gas demand for every state exogenously, while the gas consumption for power generation is 8 endogenously determined by the optimization model. The average \& peak electricity demands and non9 power gas demand are assumed to increase annually at $1.5 \%, 2 \%$ and $1 \%$ respectively. The inter-regional aggregated transmission capacity for the reference year is given in [2].

Table 8 Regional demand (GW), generation capacities (GW) and Bio-refinery capacities (Million

Gallons per year) at reference year

\begin{tabular}{|c|c|c|c|c|c|c|c|c|c|c|c|c|c|c|c|}
\hline Region & Demand & Peak & Nuclear & Coal & Oil & Hydro & $N G C C$ & $C T$ & Wind & PV solar & $P V$ thermal & Geothermal & $B C$ & $A D$ & Bio-refinery \\
\hline 1-ECAR & 75.91 & 99.06 & 8.38 & 62.12 & 0.74 & 2.04 & 12.66 & 22.90 & 0.59 & 0 & 0 & 0 & 1.22 & 0.14 & 2055 \\
\hline 2- ERCOT & 39.62 & 51.70 & 5.14 & 21.02 & 0.24 & 0.64 & 37.01 & 8.31 & 7.43 & 0 & 0 & 0 & 0.31 & 0.03 & 355 \\
\hline 3- $M A A C$ & 25.74 & 33.59 & 11.83 & 17.70 & 1.42 & 1.28 & 10.20 & 3.33 & 0.36 & 0.003 & 0 & 0 & 0.81 & 0.09 & 110 \\
\hline 4-MAIN & 25.33 & 33.05 & 13.47 & 16.11 & 0.66 & 0.53 & 5.87 & 16.17 & 1.23 & 0 & 0 & 0 & 0.12 & 0.01 & 1927 \\
\hline 5- МAPP & 23.01 & 30.02 & 4.60 & 18.95 & 1.87 & 3.08 & 5.18 & 6.35 & 5.43 & 0 & 0 & 0 & 0.66 & 0.07 & 8481 \\
\hline $6-N Y$ & 16.44 & 21.46 & 5.71 & 0.91 & 1.46 & 4.60 & 7.58 & 1.91 & 0.71 & 0 & 0 & 0 & 0.40 & 0.04 & 164 \\
\hline 7- NE & 14.05 & 18.33 & 4.64 & 1.07 & 1.72 & 1.84 & 13.09 & 0.84 & 0.08 & 0.0001 & 0 & 0 & 1.28 & 0.14 & 0 \\
\hline 8- $F L$ & 25.82 & 33.69 & 4.11 & 10.32 & 3.50 & 0.06 & 19.17 & 6.90 & 0.00 & 0 & 0 & 0 & 0.92 & 0.10 & 0 \\
\hline 9- $S T V$ & 70.62 & 92.16 & 27.52 & 37.84 & 2.07 & 11.08 & 24.31 & 25.59 & 0.03 & 0.003 & 0 & 0 & 2.22 & 0.25 & 380 \\
\hline 10- $S P P$ & 32.73 & 42.71 & 6.62 & 24.25 & 0.51 & 2.51 & 24.53 & 9.70 & 1.60 & 0 & 0 & 0 & 0.66 & 0.07 & 777 \\
\hline 11- NWP & 28.25 & 36.87 & 1.20 & 13.48 & 0.10 & 35.40 & 13.94 & 4.16 & 3.18 & 0.03 & 0.06 & 0.42 & 0.67 & 0.07 & 199 \\
\hline $12-R A$ & 18.13 & 23.66 & 4.21 & 16.69 & 0.06 & 3.59 & 16.03 & 4.82 & 1.90 & 0.02 & 0.001 & 0.00 & 0.05 & 0.005 & 210 \\
\hline 13- $C N V$ & 30.61 & 39.95 & 4.58 & 0.42 & 0.64 & 9.96 & 17.43 & 7.24 & 2.32 & 0.02 & 0.40 & 2.71 & 0.94 & 0.10 & 223 \\
\hline
\end{tabular}

Cost and performance metrics of electric generation technologies: Table 9 provides the investment and operational data for all the generation technologies, including biomass based power generation technologies [10,45]. Bio-power resources, subject to steady feedstock input, can act as base load units due to their high capacity factors. The emissions due to feedstock production, processing, transportation, and conversion stages for all fuels are modeled; but the biomass conversion (bio-power) technologies, which emit the carbon that had been stored in the feedstock during its growth, are attributed with zero CO2 emissions. It is also for this reason, coal plants emit less $\mathrm{CO} 2$ when co-fired with biomass feedstock. The investment cost of geothermal generation technology varies with geography due to the varying drilling depth required to reach suitable temperature underground. These investment costs and the geographically varying capacity factors for wind and solar generation (as shown in Table 9) for the 13 regions are provided in [35]. The model also considers coal, IGCC, and NGCC units with carbon capture and sequestration (CCS) installations. Though CCS helps in decreasing CO2 emissions by about $85 \%$ (which may be necessary for new coal unit investments, according to EPA regulation 111(b) [46]), they do come with increased capital and operating costs.

Fuel prices: Regarding the fuels for power generation, four coal varieties are modeled, to reflect their geographically-varying cost and availability. The varieties, their conversion efficiencies (function of their energy content and generator's thermal efficiency) and emissions [47] are given in Table 10. For the gas network- wellhead prices [48], production capacities [49], imports, pipeline and storage capacities are all characterized based on geography [17]. The production data does indicate increasing withdrawals from shale gas wells over the past 2-3 years, especially in Texas, Arkansas, Pennsylvania, and Louisiana. As a result, the wellhead gas prices compared to year 2008 have reduced by about $40 \%$ all over the nation, hovering around $\$ 4-5 /$ thousand cubic feet. On top of this wellhead price, the model adds a pipeline and distribution cost of about $\$ 2 /$ thousand cubic feet before the gas reaches end user. Oil and nuclear fuels are 
1 priced at $\$ 3 /$ gallon and $\$ 27.86 /$ pound, respectively. The $\mathrm{CO}_{2}$ emissions during the production of natural 2 gas and oil are about 21.72 short ton/Million cubic feet and 2472.02 short ton/million gallons respectively $3 \quad[47,50]$.

Table 9 Conversion plant investment and operational characteristics

\begin{tabular}{|c|c|c|c|c|c|}
\hline & Capacity Factor & Investment Cost $(M \$ / G W)$ & Lifespan (years) & tional Cost $-O \& M(M \$ / G W h)$ & $\mathrm{CO}_{2}$ (Short ton/GV \\
\hline Generation Technology & 0.95 & 3156 & 60 & 0.006484 & 8.51 \\
\hline Coal & 0.85 & 1788 & 40 & 0.009085 & 919.35 \\
\hline Coal $w / C C S$ & 0.85 & 3178 & 40 & 0.014506 & 136.83 \\
\hline$I G C C$ & 0.85 & 2673 & 40 & 0.006667 & 865.10 \\
\hline$I G C C w / C C S$ & 0.85 & 3622 & 40 & 0.010137 & 128.76 \\
\hline$N G C C$ & 0.75 & 827 & 30 & 0.004596 & 407.07 \\
\hline$N G C C w / C C S$ & 0.75 & 1633 & 30 & 0.006756 & 62.72 \\
\hline Oil & 0.85 & 1655 & 30 & 0.005284 & 808.10 \\
\hline$C T$ & 0.2 & 551 & 30 & 0.010619 & 555.69 \\
\hline Geothermal & 0.9 & $3149-7747$ & 50 & 0.021788 & 123.57 \\
\hline Solar PV & $0.1-0.25$ & 6865 & 30 & 0.003754 & - \\
\hline Solar thermal & $0.1-0.25$ & 4547 & 30 & 0.019215 & - \\
\hline Wind & $0.1-0.5$ & 1568 & 25 & 0.011362 & - \\
\hline Offshore & $0.2-0.4$ & 2877 & 25 & 0.015556 & - \\
\hline OTEC & 0.3 & 6163 & 50 & 0 & - \\
\hline Tidal & 0.3 & 18286 & 50 & 0.012428 & - \\
\hline Hydro & 0.5 & - & 100 & 0.004277 & - \\
\hline IPCC & 0.85 & 3311 & 30 & 0.028662 & - \\
\hline Combustion (BC) & 0.85 & 2000 & 30 & 0.009085 & - \\
\hline Gasification (BG) & 0.85 & 3000 & 35 & 00671 & - \\
\hline Anaerobic digestion (AD) & 0.85 & 1850 & 20 & \multirow{2}{*}{$\begin{array}{c}0.00952 \\
0.03\end{array}$} & - \\
\hline Bio-refinery & 1 & 3.51 & 25 & & $774.4-1310.3$ \\
\hline & & (M\$/Million Gallons Year) & & (M\$/Million Gallons) & $\begin{array}{c}\text { (Short ton/Millio } \\
\text { Gallons) }\end{array}$ \\
\hline \multicolumn{6}{|l|}{6} \\
\hline \multicolumn{6}{|c|}{ Table 10 Coal varieties and characteristics } \\
\hline \multicolumn{2}{|c|}{ Coal Type/ Generation } & $\begin{array}{c}\text { Coal } \\
\text { (GWh/thousand short ton) }\end{array}$ & $\begin{array}{c}\text { IGCC } \\
\text { (GWh/thousand short ton) }\end{array}$ & \multicolumn{2}{|c|}{$\begin{array}{c}\mathrm{CO}_{2} \text { emissions during production (short ton/ } \\
\text { thousand short ton) }\end{array}$} \\
\hline \multicolumn{2}{|c|}{ Lignite } & 1.915 & 2.072 & \multicolumn{2}{|l|}{87.49} \\
\hline Bituminous $\left(A_{l}\right.$ & lachia) & 2.616 & 2.829 & 169.40 & \\
\hline Bituminous ( & atral) & 2.140 & 2.315 & 108.83 & \\
\hline Sub-bitum & & 2.181 & 2.359 & 110.89 & \\
\hline
\end{tabular}

\section{B. Transportation sector modeling and data assumptions}

As mentioned in Section IV, the transportation sector consists of freight and passenger systems.

11 Passenger transportation is represented both at interstate and intra-regional (13 electric regions mentioned in appendix Section VII.A) levels. Freight transportation is represented at the interstate level only.

Intra-regional passenger transportation: The intra-regional passenger transportation is represented in terms of the number of LDVs required per year within each region. For instance, Fig. 12 shows regional demand for LDVs in the 13 U.S. regions. This demand is assumed to increase at $1 \%$ per year. Initially this demand is assumed to be served by gasoline vehicles alone, with the model embedded with the ability to invest in conventional gasoline vehicles, compressed natural gas vehicles (CNVs) and plug-in hybrid electric vehicles (PHEVs) from year 2 onwards. The CNV's refueling station cost is assumed to be \$3Million/100 diesel gallon equivalents of gas dispensed in a month [51]. The existing refueling station capacities are estimated based on the current state-level gas consumption for LDVs, which on an average is only about $0.1 \%$ of the total gas consumption, except in a few states like CA with $0.6 \%$ [44]. Hence, it is assumed that the existing pipeline and storage infrastructures are sufficient to support any increase in CNVs. The emissions from CNVs are assumed to be based on gas consumption, which amounts to 65 short tons of $\mathrm{CO}_{2}$ per million cubic feet of gas. An LDV is assumed to travel on an average 11,882 miles per year. The gasoline vehicle is assumed to have an average mileage of 23 miles per gallon and the PHEV about 40 miles per gallon of gasoline. The PHEV is also assumed to consume about $87.1 \mathrm{kWh}$ of electricity 
1 each month. The CNVs are assumed to do about 28 miles per gasoline gallon equivalent (GGE, where 1

2 GGE $=\sim 126.7$ cubic feet of gas).

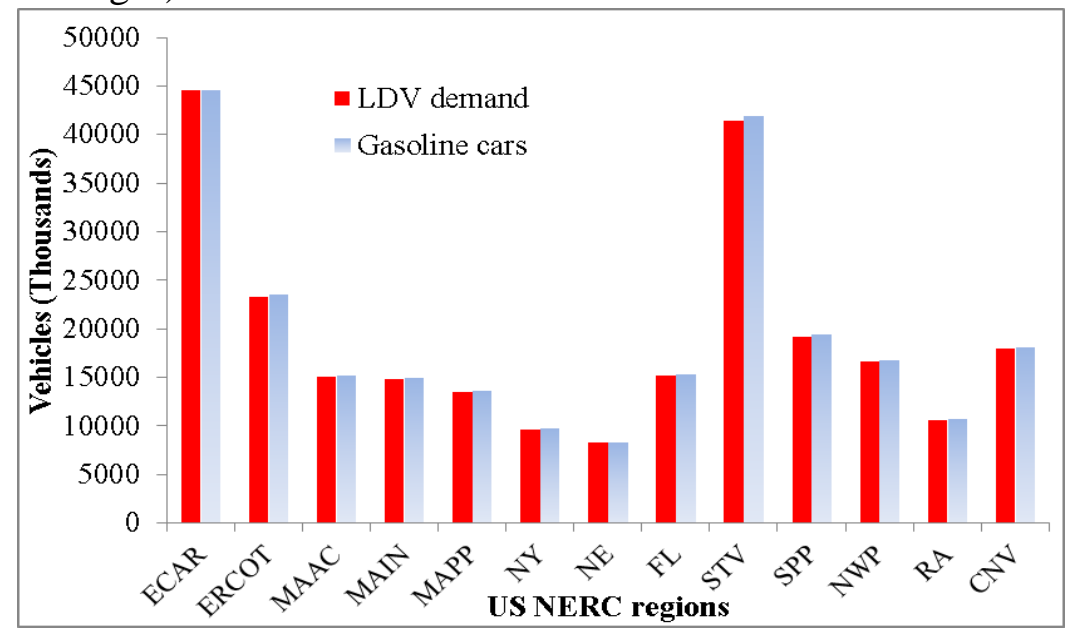

Fig. 12 U.S. regional LDV demand and gasoline cars available at reference year

Inter-state passenger transportation: In the case of interstate passenger transportation, the passenger network is modeled using 235 bi-directional arcs including 95 arcs connecting adjacent states and 140 arcs connecting non-adjacent states (to capture long distance interstate passenger travels by air, as shown in Figure 5 of [18]). Reference [18] also provides the source and method of computing interstate freight and passenger transportation demand at the reference year. The interstate passenger demand is assumed to increase at 3\% per year. Decision variables are transportation demand allocation via diesel trucks and diesel trains in each interstate arc for freight transportation, and for passenger transportation utilization of gasoline cars, PHEVs, air and high-speed rail (HSR). The operational and investment data for these fleets are provided in Table 11. Since the interstate transportation demand allocation among the various fleets are optimized at yearly time intervals over the planning horizon, the study models yearly frequencies for each fleet, as a function of interstate arc lengths [18].

Inter-state freight transportation: In the case of interstate freight transportation, the freight network is modeled using 95 bi-directional arcs that connect pairs of nodes between adjacent states (as shown in Figure 4 of [18]). The demand for coal and biomass feedstock transportation is induced by the respective generation units, and the transportation demand for other non-energy freight such as wood, gravel, chemical etc. are exogenously input to the model. The mode choices for freight transportation include diesel trucks and trains, and for passenger transportation include light duty passenger vehicles (LDVs), airplanes, and electric rails (high speed rails (HSR). The decision variables in the model for transportation sector include demand allocation (i.e., freight) via diesel trucks and diesel trains in each interstate arc for freight transportation. In the case of passenger transportation, the utilization of LDVs (gasoline cars and plug-in hybrid electric vehicles (PHEVs)), airplanes and high-speed rail (HSR) for carrying passenger demand across the various inter-state arcs and how many LDVs are required to provide intra-state vehicles demanded.

Transportation fuel prices: Considering transportation fuels, i.e., gasoline, jet fuel and diesel, their costs are assumed to be $\$ 3.8, \$ 3.3$ and $\$ 4$ per gallon, respectively, while their $\mathrm{CO}_{2}$ emissions are assumed to be 13361, 14211, and 14761 short ton/million gallons, respectively (which also includes emissions incurred at oil refineries). The capacities of petroleum refineries are more or less constant over several years at around 17.9 million barrels of crude oil per calendar day [52], with half of the operable refineries retiring, while the other half (about 140 plants) seeing size expansions and efficiency improvements. Over the past 20-30 years, no new facility has been built due to stringent air and water cleanliness standards 
requirements, economic recession and declining market. So the model assumes no future growth in oil refinery capacities. The cost and carbon emissions of drop-in biofuels depend on the feedstocktransportation-conversion pathway, which will be discussed in the next sub-section. In this study, the biofuels are assumed to share the same distribution and refueling infrastructures as the gasoline and diesel fuels. With the ever increasing fuel demand from conventional gasoline LDVs and national policies driving economy towards carbon reduction, the growth of bio-refineries that provide renewable liquid transportation fuel are on the rise. Table 8 provides existing regional capacities in million gallons per year (MGY) [53], and Table 9 provides investment and operational characteristics of bio-refineries [28, 54]. While the vehicles that use biofuels are assumed to contribute zero net-carbon due to the carbon sequestration at the feedstock growth stage, the bio-refineries may be attributed with emissions of about 1310.3 or 774.4 short ton/million gallons, depending upon the practices followed in the biofuel production processes such as less fossil fuel use, and avoided emissions credit for using co-products in cattle diet that replaces some percentage of urea, corn, soybean, and also reduces methane emissions [29].

Table 11 Fleet operational and investment characteristics

\begin{tabular}{|c|c|c|c|c|c|c|c|}
\hline Mode & $\begin{array}{c}\text { Fuel (Gallon / } \\
\text { vehicle-mile) }\end{array}$ & $\begin{array}{c}\text { Electricity }(\boldsymbol{k W h} / \\
\text { vehicle-mile })\end{array}$ & $\begin{array}{c}\text { Occupancy, } \eta \\
\text { (kilotons or } \\
\text { Passengers) }\end{array}$ & $\begin{array}{c}\text { O\&M } \\
(\$ / \text { vehicle-mile })\end{array}$ & $\begin{array}{c}\text { Investment } \\
(M \$ / \text { Vehicle })\end{array}$ & $\begin{array}{l}\text { Lifespan } \\
\text { (years) }\end{array}$ & $\begin{array}{c}\text { Yearly } \\
\text { retirement }(\%)\end{array}$ \\
\hline Diesel Truck & 0.169 & - & 0.025 & 0.255 & 0.128 & 25 & 0.5 \\
\hline Diesel Rail & 16.65 & - & 11.5 & 47.30 & 1.790 & 50 & 0.5 \\
\hline Gasoline Car & 0.044 & - & 1.63 & 0.156 & 0.0189 & 12 & 8.3 \\
\hline PHEV & 0.026 & 0.340 & 1.63 & 0.156 & 0.038 & 12 & 8.3 \\
\hline$C N V s(G G E)$ & 0.0357 & - & 1.63 & 0.156 & 0.028 & 12 & 8.3 \\
\hline Airplane & 2.248 & - & 229 & 8.90 & 165.0 & 30 & 3 \\
\hline HSR Train & - & 14.924 & 260 & 46.90 & 49.30 & 30 & 3 \\
\hline
\end{tabular}

\section{ACKNOWLEDGEMENT}

This material is based upon the work supported by the National Science Foundation, under Grant No. 0835989. The authors would like to acknowledge Dr. Trieu Mai at National Renewable Energy Laboratory (NREL), Golden, USA for his comments. Opinions expressed in this paper, however, as well as any errors or omissions, are the authors' alone.

\section{REFERENCES}

[1] "Inventory of U.S. Greenhouse Gas Emissions and Sinks: 1990-2011," U.S. Environmental Protection Agency, EPA 430-R13-001, April 2013, http://www.epa.gov/climatechange/Downloads/ghgemissions/US-GHG-Inventory-2013-Main-Text.pdf

[2] V. Krishnan, T. Das, E. Ibanez, C. Lopez, and J. McCalley, "Modeling Operational Effects of Wind Generation within National Long-term Infrastructure Planning Software, ” IEEE Trans. Power Syst., Vol. 28 (2), pp. 1308-1317, May 2013

[3] Q. Qi and J. McCalley, "Using NETPLAN to analyze environmental impacts on generation expansion planning," IEEE PES General Meeting, San Diego, CA, Jul 2012

[4] G. E. Metcalf, "Market-based Policy Options to Control U.S. Greenhouse Gas Emissions," Journal of Economic Perspectives, Vol. 23, No. 2, pp. 5-27, Spring 2009

[5] J. Gifford and R. C. Brown, "Four economies of sustainable automotive transportation," Biofuels, Bioproducts and Biorefining, 5(3):293-304, 2011

[6] J. McCalley, V. Krishnan, K. Gkritza, R. Brown, and D. Mejia-Giraldo, "Planning for the Long Haul: Investment Strategies for National Energy and Transportation Infrastructures," IEEE Power and Energy Magazine, vol.11, no.5, pp.24-35, Sept. 2013

[7] Z. Haq, "Biomass for electricity generation," Energy Information Administration, US Department of Energy, Washington, DC, 2002, http://www.eia.doe.gov/oiaf/analysispaper/biomass/pdf/biomass.pdf

[8] R. C. Brown, Thermochemical Processing of Biomass: Conversion into Fuels, Chemicals, and Power, Wiley \& Sons, 2011

[9] M. K. Mann, and P. L. Spath, "The Net CO2 emissions and energy balances of biomass and coal-fired power system," National Renewable Energy Laboratory: Golden, CO, 2006

[10] Renewable energy technologies: cost analysis series - "Biomass for Power Generation," Volume 1: Power Sector, Issue 1/5, International Renewable Anergy Agency (IRENA), June 2012, http://www.irena.org/DocumentDownloads/Publications/RE_Technologies_Cost_Analysis-BIOMASS.pdf 
[11] D. R. Johnson, A. E. Curtright, and H. H. Willis, "Identifying key drivers of greenhouse gas emissions from biomass feedstocks for energy production," Environmental Science \& Policy, Vol. 33, pp. 109-119, Nov. 2013

[12] P.W. Tittmann, N.C. Parker, Q.J. Hart, B.M. Jenkins, A spatially explicit techno-economic model of bioenergy and biofuels production in California, Journal of Transport Geography, Volume 18, Issue 6, November 2010, Pages 715-728

[13] Yun Bai, Taesung Hwang, Seungmo Kang, Yanfeng Ouyang, Biofuel refinery location and supply chain planning under traffic congestion, Transportation Research Part B: Methodological, Volume 45, Issue 1, January 2011, Pages 162-175

[14] Keith Crane, Aimee E. Curtright, David S. Ortiz, Constantine Samaras, Nicholas Burger, "The economic costs of reducing greenhouse gas emissions under a U.S. national renewable electricity mandate," Energy Policy, Volume 39, Issue 5, May 2011, Pages 2730-2739

[15] Bain, R.; Denholm, P.; Heath, G.; Mai, T.; Tegen, S., "Biopower Technologies," Chapter 6, National Renewable Energy Laboratory, Renewable Electricity Futures Study, Vol. 2, Golden, CO: National Renewable Energy Laboratory; pp. 6-1 - 6-58, 2012

[16] U.S. EIA, Annual Energy Outlook 2014, Early Release Overview http://www.eia.gov/forecasts/aeo/er/pdf/0383er(2014).pdf [17] E. Ibanez, "A multiobjective optimization approach to the operation and investment of the national energy and transportation systems", Theses and Dissertations, Paper 11948, 2011, http://lib.dr.iastate.edu/etd/11948

[18] V. Krishnan, E. Kastrouni, D. Pyrialakou, K. Gkritza, and J. McCalley, "An Optimization Model of Energy and Transportation Systems: Assessing the High-Speed Rail Impacts in the United States," accepted, to appear in Transportation Research Part C, submitted version available online: https://www.ece.iastate.edu/research/netscore-21/list-of-publications/

[19] A. Liu, Q. Zheng, J. Ho, V. Krishnan, B. Hobbs, M. Shahidehpour, and J. McCalley, "Co-optimization of Transmission and Other Supply Resources," NARUC Project No. 3316T5, prepared for the Eastern Interconnection States Planning Council (EISPC), September 1, 2013

[20] P. Sullivan, W. Cole, N. Blair, E. Lantz, V. Krishnan, T. Mai, D. Mulcahy, and G. Porro, "2015 Standard Scenarios Annual Report: U.S. Electric Sector Scenario Exploration,” National Renewable Energy Laboratory Technical Report, NREL/TP-6A20-64072, July 2015

[21] T.R. Brown, R. Thilakaratne, R.C. Brown, and G. Hu, "Techno-economic analysis of biomass to transportation fuels and electricity via fast pyrolysis and hydroprocessing," Fuel 106, 463-469, 2013

[22] Perlack RD, Wright LL, Turhollow AF, Graham RL, Stokes BJ, and Erbach DC, "Biomass as feedstock for a bioenergy and bioproducts industry: the technical feasibility of a billion-ton annual supply," April 2005

[23] A. Milbrandt, "A Geographic Perspective on the Current Biomass Resource Availability in the United States," Technical Report NREL/TP-560-39181, December 2005, http://www.nrel.gov/docs/fy06osti/39181.pdf

[24] Biomass Maps, Dynamic maps, GIS data and analysis tools, National Renewable Energy Laboratory, Golden, http://www.nrel.gov/gis/biomass.html

[25] U.S. Department of Energy, “U.S. Billion-Ton Update: Biomass Supply for a Bioenergy and Bioproducts Industry,” R.D. Perlack and B.J. Stokes (Leads), ORNL/TM-2011/224, Oak Ridge National Laboratory, Oak Ridge, TN. 227p, 2011

[26] Bioenergy Knowledge Discovery Framework, US department of Energy, https://bioenergykdf.net/

[27] STATPLANET \& STATTrends, USER GUIDE, v.3.2 May 2013, http://www.statsilk.com/software/statplanet

[28] Y. Gao, "Evaluation of Pre-processing and Storage Options in Biomass Supply Logistics: A Case Study in East Tennessee," Master's Thesis, University of Tennessee, 2011, http://trace.tennessee.edu/utk_gradthes/971

[29] A. J. Liska et. al., "Improvements in Life Cycle Energy Efficiency and Greenhouse Gas Emissions of Corn-Ethanol," Journal of Industrial Ecology,

Vol. 13 (1), pp 58-74, Feb. 2009

[30] S. C. Brechbill and W.E. Tyner, "The economics of biomass collection, transportation and supply to Indiana cellulosic and electric utility facility,” Working Paper \#08-03, Dept. of Agri. Econ., Purdue University, 2008

[31] J. Bates, O. Edberg and C. Nuttall, "Minimising greenhouse gas emissions from biomass energy generation," Environment Agency, April 2009

[32] Energy and Environmental Analysis, Inc., an ICF International Company, and Eastern Research Group, Inc. (ERG), "Biomass Combined Heat and Power Catalog of Technologies," for the U. S. Environmental Protection Agency, Combined Heat and Power Partnership, September 2007, http://www.epa.gov/chp/documents/biomass_chp_catalog.pdf

[33] Biomass Energy Resource Center, "Biomass Supply and Carbon Accounting for Southeastern Forests," Feb 2012, http://www.southernenvironment.org/uploads/publications/biomass-carbon-study-FINAL.pdf

[34] GCEP Energy Assessment Analysis, "An Assessment of Biomass Feedstock and Conversion Research Opportunities," Technical Assessment Report, Stanford University Global Climate \& Energy Project, 2005, http://gcep.stanford.edu/pdfs/assessments/biomass_assessment.pdf

[35] V. Krishnan, J. D. McCalley, S. Lemos, J. Bushnell, "Nation-wide transmission overlay design and benefits assessment for the U.S.," Energy Policy, Vol. 56, May 2013, pp. 221-232

[36] E. Ibanez, et. al. "Resiliency and robustness in long-term planning of the national energy and transportation system," International Journal of Critical Infrastructures, 2014 
[37] V. Krishnan, L. Gonzalez-Marciaga, and J. McCalley, A planning model to assess hydrogen as an alternative fuel for national light-duty vehicle portfolio, Energy, Vol. 73, 14 August 2014, Pages 943-957

[38] Energy Information Administration, Office of Integrated Analysis and Forecasting, U.S. Department of Energy, "The National Energy Modeling System: An Overview 2009" Washington D.C., October 2009, www.eia.doe.gov/oiaf/aeo/over view/ [39] A. Quelhas, E. Gil, J. McCalley, and S. Ryan, "A multiperiod generalized network flow model of the U.S. integrated energy system: Part I - model description,” IEEE Trans. Power Syst., 22 (2), pp.829-836, 2007

[40] V. Krishnan and J. McCalley, "Building Foresight in Long-Term Infrastructure Planning Using End-Effect Mitigation Models," IEEE Systems Journal, April 2015

[41] Washington post: http://www.washingtonpost.com/graphics/national/power-plants/

[42] Ruth, M.; Mai, T.; Newes, E.; Aden, A.; Warner, E.; Uriarte, C.; Inman, D.; Simpkins, T.; Argo, A. (2013). Transportation Energy Futures Series: Projected Biomass Utilization for Fuels and Power in a Mature MarketPDF. 174 pp.; NREL Report No. TP-6A20-53336; DOE/GO-102013-3707

[43] U.S. Energy Information Administration, Form EIA-860, 'Annual Electric Generator Report' and Form EIA-860M, 'Monthly Update to the Annual Electric Generator Report.', Accessed Feb $20 \quad 2014$ http://www.eia.gov/electricity/annual/html/epa_04_07_b.html

[44] US Energy Information Administration (EIA), Independent Statistics \& Analysis, Natural Gas Consumption by End Use (Million Cubic Feet), 6/30/2014, http://www.eia.gov/dnav/ng/ng_cons_sum_dcu_nus_a.htm

[45] R. Tidball, J. Bluestein, N. Rodriguez, and S. Knoke, "Cost and Performance Assumptions for Modeling Electricity Generation Technologies,” ICF International, NREL/SR-6A20-48595, November 2010 http://www.nrel.gov/docs/fy11osti/48595.pdf

[46] Center for Climate and Energy Solutions (C2ES), "EPA regulation of greenhouse gas emissions from new power plants," Nov. 2013, http://www.c2es.org/docUploads/epa-new-q-a.pdf

[47] J. H. Edwards, I.E. Galbally, C.P. Meyer, and I.A. Weeks, "Lifecycle emissions and energy analysis of LNG, oil and coal," CSIRO Division of Atmospheric Research, Report to WOODSIDE PETROLEUM Pty Ltd, 1996

[48] US Energy Information Administration (EIA), Independent Statistics \& Analysis, Natural Gas Prices (Dollars per Thousand Cubic Feet), 6/30/2014, http://www.eia.gov/dnav/ng/ng_pri_sum_a_EPG0_FWA_DMcf_a.htm

[49] US Energy Information Administration (EIA), Independent Statistics \& Analysis, Natural Gas Gross Withdrawals and Production (Volumes in Million Cubic Feet), Release Date: 6/30/2014,

http://www.eia.gov/dnav/ng/ng_prod_sum_a_EPG0_VGM_mmcf_a.htm

[50] T. J. Skone, et. al. "Life Cycle Assessment of Natural Gas Extraction, Delivery and Electricity Production," Office of Strategic Energy Analysis and Planning, National Energy Technology Laboratory (NETL), US DoE, 2012, http://www.netl.doe.gov/File\%20Library/Research/Energy\%20Analysis/Publications/LCA-NGExtrDelivElectProd01252012.pdf

[51] C. Johnson, "Business Case for Compressed Natural Gas in Municipal Fleets," Technical Report NREL/TP-7A2-47919, June 2010

[52] Energy Information Administration (EIA), Refinery Capacity 2014, Form EIA-820, "Annual Refinery Report.", Accessed June 30 2014, http://www.eia.gov/petroleum/refinerycapacity/table1.pdf

[53] Renewable Fuels Association, "Falling Walls \& Rising Tides," 2014 Ethanol Industry Outlook, Jan 2014, http://ethanolrfa.3cdn.net/2704ddcafa38cadd54_mlblcbx7o.pdf

[54] APEC Energy Working Group, "Biofuel Costs, Technologies and Economics in APEC Economies," Asia-Pacific Economic Cooperation (APEC), Dec 2010, http://www.biofuels.apec.org/pdfs/ewg_2010_biofuel-production-cost.pdf 